\title{
Microsatellite Instability in Colorectal Cancer
}

\author{
C. Richard Boland and Ajay Goel \\ Gl Cancer Research Laboratory, Division of Gastroenterology, Department of Internal Medicine, \\ Sammons Cancer Center and Baylor Research Institute, Baylor University Medical Center, \\ Dallas, Texas
}

\section{Abstract}

Microsatellite instability (MSI) is a hypermutable phenotype caused by the loss of DNA mismatch repair activity. MSI is detected in about $15 \%$ of all colorectal cancers; $3 \%$ are of these are associated with Lynch syndrome and the other $12 \%$ are caused by sporadic, acquired hypermethylation of the promoter of the $M L H 1$ gene, which occurs in tumors with the $\mathrm{CpG}$ island methylator phenotype. Colorectal tumors with MSI have distinctive features, including a tendency to arise in the proximal colon, lymphocytic infiltrate, and a poorly differentiated, mucinous or signet ring appearance. They have a slightly better prognosis than colorectal tumors without MSI and do not have the same response to chemotherapeutics. Discovery of MSI in colorectal tumors has increased awareness of the diversity of colorectal cancers and implications for specialized management of patients.

\section{Keywords}

Lynch Syndrome; DNA Mismatch Repair; Hereditary Nonpolyposis Colorectal Cancer

\begin{abstract}
Cancers can be characterized by patterns of changes in gene expression. Genes that mediate tumorigenesis can be broadly characterized as oncogenes, which are activated by alterations; and tumor suppressor genes, which are inactivated during tumorigenesis. Oncogenes can encode growth factors or their receptors, signaling molecules, regulators of the cell cycle, and other factors that regulate cell proliferation and survival. Their oncogenicity can be induced by mutations that lead to overactive gene products, amplifications that alter copy number, alterations or rearrangements that affect promoter function, or modified interactions with regulators of transcription or epigenetic modification. Tumor suppressors restrain growth and proliferation, passage through the cell cycle, motility, invasion, or other functions related to stable differentiation. Genes that encode tumor suppressors are commonly inactivated by deletion, mutations, promoter methylation, or other changes in regulation. Colorectal cancers (CRCs) develop gradually over a long period of time through the sequential accumulation of genetic alterations that overcome the redundant control mechanisms built into each cell. ${ }^{1}$ Only a few mutations are common to most colorectal
\end{abstract}

\footnotetext{
Address requests for reprints to: C. Richard Boland, MD, GI Cancer Research Laboratory (250 Hoblitzelle), Division of Gastroenterology, Department of Internal Medicine, Sammons Cancer Center and Baylor Research Institute, Baylor University Medical Center, 3500 Gaston Avenue, Dallas, Texas 75246., rickbo@ baylorhealth.edu; fax (214) 818-9292.

Conflicts of interest

The authors disclose no conflicts.

Supplementary Material

Note: The first 50 references associated with this article are available below in print. The remaining references accompanying this article are available online only with the electronic version of the article. Visit the online version of Gastroenterology at www.gastrojournal.org, and at doi:10.1053/j.gastro.2009.12.064.
} 
tumors, but each tumor has a unique combination of genetic alterations. ${ }^{2}$ It is possible that no 2 CRCs are alike, a daunting consideration for the rational planning of treatment.

\section{Models of CRC Pathogenesis}

It was not immediately obvious that CRCs would be so diverse genetically. The initial attempt to characterize multistep carcinogenesis resulted in a novel conceptual model in which specific genetic alterations were associated with the sequential evolution of the neoplastic phenotype in the colon. In the model proposed by Fearon and Vogelstein, inactivation of the adenomatous polyposis coli (APC) gene led to the initial appearance of the adenoma from normal colonic mucosa, mutations in KRAS were associated with growth of the adenoma, genetic alterations (mainly deletions) to genes on chromosome 18q resulted in adenoma growth and progression, and biallelic loss or inactivation of $p 53$ mediated the adenoma-to-carcinoma transition. ${ }^{3}$ Chromosomal instability and loss of heterozygosity (LOH) are important steps in this process, and there is a relationship between the degree of LOH and tumor progression. ${ }^{4,5}$ Although this model, proposed in 1990, has been useful, only a few CRCs actually evolve along this pathway. ${ }^{2,6}$

Fearon and Vogelstein ${ }^{3}$ were careful to characterize the genetic changes as "alterations" and did not presume to have determined the mechanisms involved. Some of the alterations were point mutations (as occurs in $K R A S$ ), whereas many were deletions of relatively large pieces of chromosome (such as on 18q, in which an arm or whole chromosome can be deleted).

Point mutations can occur through a number of mechanisms, such as chemical carcinogenesis or unrepaired "natural" degradation of DNA. A diet-induced increase in proliferation can create replicative errors in DNA that exceed the ability of the cell to repair them. The origin of genetic deletions and LOH is complex and is addressed in the accompanying review of chromosomal instability.

A controversy emerged between investigators who thought that some type of genomic instability was required to produce all the mutations that are present in colorectal tumors vs investigators who reasoned that cells continuously generate a small number genetic alterations, and that mutations that provide proliferative or survival advantages are selected for during clonal expansion. It is not clear which model occurs during CRC pathogenesis, but at least 1 type of colorectal tumor is caused by the hypermutable phenotype known as micro-satellite instability (MSI).

\section{MSI as a Unique Mechanism in Tumor Development}

Shortly after publication of the multistep genetic model of colorectal carcinogenesis, many investigators began searching the genome for novel tumor suppressor genes using powerful techniques. In 1992, Manuel Peru-cho used an arbitrarily primed polymerase chain reaction (PCR), extracting DNA from colonic tissues and amplifying thousands of sequences using a small number of randomly chosen PCR primers. This technique yielded unique but reproducible electrophoretic signatures from each sample. ${ }^{7}$ Perucho's group used arbitrarily primed PCR to amplify matched samples of DNA from colorectal tumors and adjacent normal colonic tissue, separated the PCR products electrophoretically, and compared the results to identify differences in PCR amplicons between normal and tumor tissues-DNA missing from the tumor would presumably represent somatic cell deletions that were candidate regions for new tumor suppressor genes.

Deleted DNA bands were found in most colorectal tumor samples. ${ }^{8}$ However, upon careful analysis of the comparative autoradiograms, the authors noted that $12 \%$ of $\sim 130$ tumors had bands that were not actually deleted, but were shorter in length and migrated slightly further down the gel. They analyzed the sequences in these bands and discovered that they 
contained simple repetitive sequences (ie, microsatellites), principally in polyadenine $\left(A_{n}\right)$ tracts associated with Alu sequences. The DNA obtained from this group of tumors had undergone somatic deletion of $\geq 1$ of the adenine residues. The method was unbiased and quantitative, permitting the estimate that each tumor contained $\sim 10^{5}$ such mutations. The tumors with these "ubiquitous somatic mutations at simple repeated sequences" had unique clinical and pathological characteristics. First, the tumors with these deletion mutations were significantly more likely to arise in the proximal colon, were less likely to be invasive, were less likely to have mutations in $K R A S$ or $p 53$, were more likely to appear poorly differentiated, and came from younger patients. Based upon these findings, the authors concluded that these deletions represented a unique pathway to tumor development and predicted that the "catastrophic loss of fidelity in the replication machinery of normal cells" that caused them might be hereditary, although they had no evidence for this. ${ }^{8}$

Simultaneously, Stephen Thibodeau's laboratory was studying dinucleotide repeat sequences (a type of micro-satellite) that were useful as tools for genetic mapping and analysis of $\mathrm{LOH}$, and looking for novel tumor suppressor genes on chromosomes 5q, 15q, $17 \mathrm{p}$, and $18 \mathrm{q}$ in colorectal tumors. They observed deletion mutations in the $[\mathrm{CA}]_{\mathrm{n}}$ sequences (called "C A repeats") in these regions and coined the term microsatellite instability (which they termed $M I N$ ). They detected MSI in 25 of 90 CRCs (28\%), and noted that these aberrations were heterogeneous in different tumors. They referred to a large deletion or expansion within the $[\mathrm{CA}]_{\mathrm{n}}$ tract as a "type I mutation," and called a single 2-base-pair repeat change a minor or "type II mutation." The implications of type I vs II mutations have never been elucidated, but they might reflect the cumulative nature of mutations in dinucleotide repeat sequences as they occur over time. ${ }^{9}$ Importantly, they found that $89 \%$ of tumors with MSI were in the proximal colon and that the patients with MSI CRCs had a better prognosis; like Perucho, Thibodeau et al recognized that this represented a unique pathway for tumor development that "does not involve loss of heterozygosity." 10

Studies from an international consortium led by Bert Vogelstein in the United States and Albert de la Chapelle in Finland helped elucidate the clinical implications of MSI, using microsatellites (mainly, but not exclusively dinucleotide repeats) as tools for genome-wide linkage analysis of hereditary CRC. Aaltonen et al found significant linkage at chromosome $2 p$ using the marker D2S123 in 2 large kindreds with Lynch syndrome (then called hereditary nonpolyposis colorectal cancer [HNPCC]). ${ }^{11}$ The authors used D2S123 to look for $\mathrm{LOH}$ at that locus in the CRC DNA, testing the hypothesis that this was the site of the tumor suppressor gene that caused hereditary CRC and that the second hit to the gene would be LOH. Instead, they observed MSI with the marker and then noted that deletion mutations in microsatellite sequences were widespread in hereditary CRCs. They referred to this as the replicative error phenotype. More importantly, they found MSI in 13\% of sporadic CRC cases and correctly reasoned that the hereditary tumors and a subset of sporadic tumors shared a unique but common pathway of tumor development. ${ }^{12}$

It became apparent that a subset of colorectal tumors (at least $12 \%$ and perhaps as much as $28 \%$ ) were characterized by a large number of mutations at microsatellite sequences, formed in the proximal colon, had unique clinical features (such as a better prognosis than other types of CRC), and were hereditary. MSI was the first DNA marker available to identify hereditary CRC, although none of the investigators who discovered MSI in CRC understood mechanisms by which it developed.

A series of investigations led to the realization that MSI arises from defects in the DNA mismatch repair (MMR) system and the identification of the 4 genes that cause Lynch syndrome. Interestingly, microbial geneticists predicted that defects in the MMR system 
were probably responsible for MSI. The timeframe of these discoveries are illustrated in Figure 1.

\section{DNA MMR System}

The "mutator phenotype" was discovered in bacteria in the 1970s and 1980s and was wellcharacterized by the beginning of the 1990s. ${ }^{13}$ It is caused by mutational inactivation of genes involved in DNA repair. The first human disease that was clearly associated with defects in DNA repair was xeroderma pigmentosa, a rare autosomal recessive disease caused by biallelic inactivating mutations in genes involved in nucleotide excision repair. Several other DNA repair systems had been characterized that included MMR, base excision repair, and a variety of nucleases and other DNA excision repair enzymes, yet no human diseases were associated with these.

In prokaryotes, the MMR system consists of a family of enzymes that detect S-phase DNA replication errors (ie, those that result in mismatches between the 2 strands of DNA) in which the newly synthesized strand has incorporated the wrong nucleotide. DNA polymerase sometimes makes errors incorporating the correct number of bases during replication of long repetitive DNA sequences, such as microsatellites. Slippage during replication of a repetitive sequence creates a temporary insertion-deletion loop (IDL) that can be recognized and repaired by the MMR system, along with single base-pair mismatches. If these are not repaired, during the second round of replication the original parental strand is copied correctly, but the erroneously synthesized daughter strand (with the mismatch or IDL) contains a mutation. Single base-pair mismatches result in point mutations, whereas IDLs result in frame-shift mutations that usually lead to a downstream nonsense mutation; this results in production of a truncated, nonfunctional protein. This is the basis of MSI.

MMR is more complex in yeast and mammalian systems. The yeast homologues of the bacterial $m u t S$ and $m u t L$ genes were cloned and given the names Mut S homologue (MSH) and Mut L homologue ( $M L H)$. Then, additional homologous copies of these genes were cloned from yeast, giving rise to the terms $M S H 1$ though MSH6, and $M L H 1$ through $M L H 3$. Another MutL homologue, called post-meiotic segregation-1 (PMS1), was also identified in yeast. Each of these genes had diverged from the initial mutS and $m u t L$ sequences and has been associated with specific repair functions in nuclear DNA, during meiosis, or in mitochondrial DNA. Phylogenetic analysis indicates that $M S H 1$ was the founding member of the Mut $\mathrm{S}$ family and that the homologues diverged from this progenitor gene, but no highly homologous $\mathrm{MSHI}$ gene is present in higher organisms. ${ }^{14}$

More importantly, in the yeast and other eukaryotes, MutS and MutL proteins no longer function as homodimers. Instead, MSH2 forms a heterodimer with MSH6 or MSH3, giving rise to MutS $\alpha$ or MutS $\beta$, respectively. ${ }^{15}$ These heterodimers have different relative abilities to bind to DNA mismatches and, as a result, yeast and other eukaryotes have a broader ability to recognize and repair different types of DNA misincorporation. For example, MutS $\alpha$ has a higher affinity for recognizing single base-pair mismatches. In fact, MSH6 was initially called the "GT-binding protein." 16,17 It was later discovered that the MSH3 gene encoded another MutS homologue that dimerized with MSH2 to create a complex with increased ability to bind to larger IDLs. ${ }^{18}$ The evolution of diverse homologues of mutS increased the cell's ability to recognize and repair synthetic errors in DNA and increased replication fidelity in higher organisms. The phylogeny and biochemistry of factors involved in MMR have been reviewed. ${ }^{19-22}$

Mammals have 4 homologues of the prokaryotic Mut L gene: $M L H 1, M L H 3, P M S 1$, and $P M S 2$. PMS1 was the first $m u t L$ homologue cloned in yeast; it was given a unique name 
because of its functional role in meiosis. Tracing the genes phylogenetically is complicated because the yeast $P M S 1, M L H 1, M L H 2$, and $M L H 3$ genes correspond to human $P M S 2$, $M L H 1, P M S 1$, and $M L H 3$ genes, respectively. The function of the products of the $M u t L$ homologues are not as clear as those of the $M u t S$ homologues, but the encoded proteins function as heterodimers. MLH1 and PMS2 form MutL $\alpha$, which is mediates the interaction between the MutS proteins and enzymes involved in long-patch excision in postreplication mismatch repair. However, $M L H I$ (the major $M u t L$ homologue in humans) encodes a product that can dimerize with PMS1 to form $\operatorname{MutL} \beta$, which suppresses mutagenesis in yeast but has an uncertain function in humans. Moreover, the dimer of MLH1 and MLH3 $($ MutL $\gamma)$ helps suppress IDL mutations and functions during meiosis in yeast, but its function in humans is unknown. Loss of MLH1 results in total loss of MMR activity, but loss of PMS2 can be partially compensated by MLH3. It is not known how PMS1 fits into this model, but the MLH1-PMS1 heterodimer is not part of the canonical human MMR system. This system is illustrated in the model in Figure 2.

\section{MSI is Caused by Deficiencies in MMR}

By 1993 , it was recognized that about $15 \%$ of colorectal tumors have a unique mechanism of pathogenesis; they might have been first solid tumors with subclasses that had features so distinct they could be considered as separate diseases. To identify the different pathogenic mechanisms, researchers analyzed the PCR products of colorectal tumors with MSI.

Microsatellite sequences are abundant throughout the genome; they are polymorphic among individuals but are unique and uniform in length in every tissue in each person. The heterogeneity of dinucleotide repeats made them valuable for forensic, gene mapping, and allele discrimination analyses. Figure 3 illustrates amplification of dinucleotide and mononucleotide repeats in colonic tissues using autoradiography and gel electrophoresis.

The initial published examples of MSI were autoradiograms of radiolabeled PCR products; findings in yeast indicated that defects in genes that encode MMR factors might be responsible for the MSI observed, although no human MMR genes had been cloned.

\section{MMR Genes, HNPCC, and Lynch Syndrome MSH2 and HNPCC}

Because much of the attention was focused on MSI in hereditary CRC, several groups set out to determine whether germline mutations in $M M R$ genes were responsible for Lynch syndrome. Fishel et al cloned the human $M S H 2$ gene based on its homology to the yeast sequence, mapped it to human chromosome 2p22-21 (close to the locus implicated earlier in the year ${ }^{12}$ ), and found a sequence variation in patients with familial $\mathrm{CRC}^{23}$ at the -6 position of intron 13 of $M S H 2$. It was proposed that this variant altered splicing, inactivated the gene product, and was a germline mutation that mediated CRC pathogenesis. In fact, this is a common intronic polymorphism, but it was linked (in cis) to a true inactivating mutation that was found shortly thereafter. The association between $M S H 2$ and hereditary CRC explained the MSI phenotype observed in colorectal tumor samples; $M S H 2$ is located near the locus described in the first reported linkage study.

Leach et al confirmed the role of $\mathrm{MSH} 2$ mutations in hereditary CRC, identifying germline mutations in 3 kindreds with familial CRC: 1 leucine to proline missense mutation, 1 large in-frame deletion, and 1 nonsense mutation. ${ }^{24}$ These mutations were found in multiple affected members of the kindreds but not in individuals without cancer. Parsons et al showed that the CRC cell line, HCT116, which had MSI at $[\mathrm{CA}]_{\mathrm{n}}$ sequences, was deficient in MMR activity. ${ }^{25}$ Within 7 months of the discovery of MSI in CRC, it was linked to a class of 
genes that had not previously been of interest to cancer biologists. It was recognized that colorectal tumors might develop through loss of a DNA repair mechanism and that germline mutations in at least 1 of these genes mediated HNPCC. ${ }^{26}$

\section{MLH1, PMS2, PMS1, and MSH6}

Shortly after the $2 p$ locus was linked with familial CRC, CRC in 3 Swedish families was linked to chromosome 3p21-23. ${ }^{27}$ The association between $M S H 2$ and Lynch syndrome indicated that other genes that encode MMR factors might be located on 3p, which would represent a second familial CRC locus. Two groups found $M L H 1$ on 3p21-Bronner et al identified the human homologue of yeast MLH1 and found germline mutations in multiple members of a CRC family with significant linkage to the $3 \mathrm{p}$ locus. ${ }^{28}$

At virtually the same time, the groups of Vogelstein and de la Chapelle scanned a DNA database for sequences homologous to the yeast $M L H 1$, mapped one to chromosome $3 \mathrm{p}$, and cloned the gene. Papadopoulos et al identified germline mutations in 7 members of 1 large Finnish CRC kindred that had been linked to $3 p$, found mutations in 3 more CRC kindreds, and reported a mutation in this gene in a CRC cell line. ${ }^{29}$ Using the same strategy of searching databases for homologous sequences, the human PMS1 and PMS2 genes were implicated in familial CRC shortly thereafter. ${ }^{30}$ The association between PMS 2 and CRC has been established, but the role of PMS1 in sporadic or familial CRC is not clear. In the period from December 1993 to September 1994, 3 more genes were linked to familial CRC; it took another several years to identify the relationship between the MSH6 gene ${ }^{17}$ and Lynch syndrome. ${ }^{31}$ MSH6 is associated with somewhat atypical CRC kindreds with delayed onset of the cancer, which obscured the initial efforts at discovery. Once it was realized that MSH5 families did not fit the classical expectations of the Lynch Syndrome phenotype, the case for its involvement was secured. . $^{32}$

\section{Lynch Syndrome}

The focus of MSI in CRC was immediately aimed at Lynch syndrome because of its inherited and unique features. ${ }^{33}$ These patients develop tumors at early ages, often between 20 and 30 years old. They frequently have multiple tumors, including those of the colon, rectum, endometrium, stomach, ovary, urinary tract, small intestine, and other sites, but no increase in the frequency of cancers of the breast, lung, or prostate. ${ }^{34}$ Before 1993, there was no agreement on whether this syndrome actually represented a distinct disease. ${ }^{26}$

Families with clusters of CRC were therefore evaluated in linkage studies to identify loci of putative hereditary CRC genes. The Amsterdam Criteria were developed in 1991 so that research groups would have a uniform collection of families to study. ${ }^{35}$ These criteria called for 3 CRC cases in a family in which 1 individual was a first-degree relative of the other 2, CRC occurred in at least 2 generations (in which familial polyposis was excluded), and 1 affected family member was younger than 50 years of age. The Amsterdam II Criteria were developed in 1999 to acknowledge the involvement of noncolonic tumors in the phenotype. 36

Studies of these kindreds facilitated the identification of genes responsible for this disease. Lynch syndrome is the hereditary disease caused by inactivating germline mutations in genes that encode MMR factors. ${ }^{37}$ There are 4 definite Lynch syndrome genes: $M S H 2$, MLH1, MSH6, and PMS2. ${ }^{38}$ There are 2 genes that are candidates for Lynch syndrome $\left(M L H 3^{39}\right.$ and $\left.E x o 1^{40}\right)$, but have been only rarely associated with familial CRC or the reported associations are believed to be coincidental. There has been no independent confirmation of a role for $M L H 3$ in CRC and there has been a contradictory report on the 
role of Exol in this disease. ${ }^{41}$ However, both genes are an integral part of the MMR system, so there is rationale for considering these genes.

The Amsterdam Criteria are rigorous; it was expected that these would exclude many actual Lynch syndrome families because of the small sizes of families, missing information, and other practical issues. Although this was the case, it was surprising that $40 \%-60 \%$ of families that met the Amsterdam Criteria did not have a germline mutation in an $M M R$ gene and the tumors did not have MSI. ${ }^{42,43}$ Families with non-Lynch syndrome CRC have been termed familial colorectal cancer, type $X$ by 1 large collaboration. ${ }^{42}$ These families are characterized by microsatellite-stable tumors, a lower relative risk for CRC, the absence of excess tumors outside of the colon, and later onset of CRC. The genetic basis of this group is not known.

\section{MMR Gene Mutations in Lynch Syndrome}

To diagnose Lynch syndrome, MMR genes are analyzed, preferably using exon-by-exon sequencing with PCR primers that include relevant portions of the in-tron- exon boundaries; these detect point mutations and small insertion-deletion mutations that involve DNA sequences between the primers but not larger deletions or rearrangements, such as DNA sequence that are rejoined after a break, because the breakpoints are usually located deep within introns or completely outside of the coding regions. When DNA sequencing is performed, the tracing is examined for a double signal, ie, the simultaneous presence of a wild-type and mutant nucleotide in the same sequence position. When there is a deletion of an entire exon in which the breakpoints are outside of the primers for that exon, the analysis gives normal results because only 1 strand is sequenced, and conventional techniques cannot determine whether 1 or 2 alleles are detected. Large deletions can be detected by multiplex ligation-dependent probe amplification, which quantifies the number of alleles at each exon. ${ }^{44}$ Large deletions account for $>33 \%$ of all $M S H 2$ mutations associated with $\mathrm{HNPCC}^{45}$; $M S H 2$ is located within a dense cluster of Alu sequences, which are prone to internal recombination followed by excision of the DNA loop. Large rearrangements also occur with MLHI and MSH6. ${ }^{46}$

Analysis for mutations in DNA MMR genes does not end when a sequence variation is found; interpretation is another issue. Most deletions and nonsense mutations have pathologic consequences, but missense mutations are not always interpretable. It is important to determine how well the sequence has been preserved (indicating its functional significance) and if it is located in a region where the MMR proteins interact. Disruption of regions of protein-protein interaction by a nonconservative amino acid change could disrupt complex formation and function (see Figure 4). The mutant allele might need to be cloned and its product tested in a functional assay. ${ }^{22,47}$ A proportion of mutations identified in genetic testing are reported as "variants of uncertain significance," and will remain so until we are better able to predict protein function based on its structure. It is interesting that there is a missense mutation in $M L H 1(\mathrm{c} 415 \mathrm{G} \rightarrow \mathrm{C} ; \mathrm{D} 132 \mathrm{H})$ that affects adenosine triphosphate binding of the mutant gene product, increases risk for CRC, but does not always cause MSI in CRC cells. ${ }^{48}$

\section{MSI in Sporadic CRC}

Two of the 3 initial descriptions of MSI were made in samples from sporadic colorectal tumors, rather than tumors from patients with familial CRC. ${ }^{8,10}$ Much of the subsequent attention to MSI was directed to familial CRC, but only about 3\% of all CRCs come from Lynch syndrome families. ${ }^{49,50}$ Approximately $12 \%-17 \%$ of all colorectal tumors have MSI, depending upon the methods used to detect it; ${ }^{51,52}$ (references ${ }^{51-144}$ can be found in the Supplementary Material) most CRCs with MSI are sporadic. 
The majority of colorectal tumors with MSI have lost expression of MLH1 and PMS2 protein. In 1997, Kane et al showed that $M L H 1$ was silenced by methylation in most of these tumors. ${ }^{53}$ The characteristic features of sporadic CRC with MSI include the absence of significant familial clustering, biallelic methylation of the $M L H 1$ promoter ${ }^{54}$; absence of MLH1 and PMS2 proteins; and frequent mutation (usually V600E ) in $B R A F .{ }^{55}$ The tumors are frequently diploid $(74 \%)$ and patients with sporadic colorectal tumors with MSI have a better prognosis than those with non-MSI tumors. ${ }^{56}$ Whereas patients with Lynch syndrome patients are younger than those with sporadic CRC, those with sporadic CRCs with MSI are older. Loss of $M L H 1$ expression increases with age; the gene is lost in $\sim 50 \%$ of CRC patients older than 90 years of age. ${ }^{57}$

\section{Sporadic MSI and CpG Island Methylator Phenotype}

MSI-associated sporadic CRCs arise through a process that involves the $\mathrm{CpG}$ island methylator phenotype (CIMP) ${ }^{58}$ About half of the genes in the human genome have promoters that are embedded in clusters of cytosine-guanosine residues called $\mathrm{CpG}$ islands.

${ }^{59}$ Cytosines in these regions can be methylated by DNA methyltransferases. Methylation is a means by which a cell permanently silences genes; it remains in the progeny of each cell. In vitro, it is possible to demethylate at least some promoters using the DNA methyltransferase inhibitor 5-azacytidine; however, upon removal of this agent, remethylation occurs. Histone modifications indicate which $\mathrm{CpG}$ sites are marked for permanent methylation. ${ }^{60}$

Methylation increases with advancing age, is accelerated in the colon in response to chronic inflammation, and might be an adaptive response to injury. ${ }^{61,62} \mathrm{~A}$ subset of CRCs has been identified that is characterized by CIMP. ${ }^{63,64}$ These tumors progress by methylating tumor suppressor genes and have distinctive clinical features compared to non-CIMP colorectal tumors. ${ }^{64}$ Some of the commonly methylated promoters have no apparent role in tumor development and have been labeled "methylated in tumor" or MINT genes, but methylation also occurs in promoters of known tumor suppressor genes, such as p16 and insulin-like growth factor 2, and DNA repair genes such as methylguanine methyltransferase and MLH1.

The region of the $M L H 1$ promoter in which methylation mediates gene silencing is the $3^{\prime}$ end, close to the start codon. The $5^{\prime}$ end of the promoter is also prone to methylation, but this is not of functional importance unless the methylation extends to the critical $3^{\prime}$ region. ${ }^{65}$ Therefore, specific $\mathrm{CpG}$ residues are more important than others in mediating gene silencing. Importantly, most of the CRCs with sporadic MSI come from a CIMP background, which creates an important distinction from Lynch syndrome tumors. ${ }^{66,67}$

Consequently, it is essential to know more about a colorectal tumor than whether there is MSI or not. Lynch syndrome tumors are associated with germline mutations in DNA MMR genes, ${ }^{37}$ occur in younger individuals, can have KRAS mutations (but never BRAF mutations), and are associated with a better prognosis than non-MSI tumors. ${ }^{68}$ Most sporadic colorectal tumors with MSI occur in older individuals, have BRAF mutations in about half of the cases (V600E), are associated with a background of CIMP, and are associated with a reduced mortality. Curiously, $B R A F$ mutations, which are detected in sporadic but not familial CRCs with MSI are associated with reduced mortality. ${ }^{64}$

\section{Germline Epimutations}

To aide in the diagnosis of Lynch syndrome, researchers have searched for germline mutations in a coding regions, splice sites, or promoter regions of MMR genes. However, instead of a genetic mutation, some cases of Lynch syndrome are caused by epigenetic 
inactivation of genes by promoter methylation. These events, originally described as germline epimutations, are better referred to as constitutional epimutations, to reflect the aberrant silencing of a gene that is normally active in somatic tissues in the absence of a sequence mutation. Constitutional epimutations of $M L H 1^{69-71}$ and $M S H 2^{72,73}$ have been identified in families with Lynch syndrome who have no apparent MMR gene sequence mutations. $M S H 2$ methylation can arise from a deletion in the $3^{\prime}$ end of the gene just upstream of MSH2 (TACSTD1) — the loss of the stop codon somehow results in methylation of the $\mathrm{CpG}$ island downstream, which leads to constitutional silencing of $M S H 2$. Similar to germline mutations, constitutional epimutations in $\mathrm{MSH} 2$ demonstrate classic autosomal dominant inheritance and are associated with a 50\% risk of transmission to the offspring. 73,74

\section{Pathophysiology of Colorectal Carcinogenesis with MSI}

CRCs with MSI were discovered, in part, because they were different from most other CRCs; the tumor cells had a tendency to be diploid and had less LOH. The mutational patterns were of interest because of the unique clinical features of these tumors. In 1995, Markowitz et al provided an important insight into the carcinogenetic pathway. ${ }^{75}$ Transforming growth factor- $\beta$ (TGF- $\beta$ ) signaling inhibits proliferation in the colonic epithelium; Markowitz et al showed that the TGF- $\beta$ type II receptor (TGF $\beta$ R2) was not expressed in cell lines with MSI or in xenografts of these cells grown in nude mice, but was expressed by cell lines without MSI. TGF $\beta R 2$ includes 2 microsatellite sequences. From nucleotides 1931 to 1936 , there is a 6-base pair $[\mathrm{GT}]_{3}$ sequence (the inverse of a C-A repeat) and from nucleotides 709 to 718 there are 10 consecutive adenines $\left(A_{10}\right)$. Deletion mutations in these microsatellite sequences create frame shifts that inactivate the gene product. These were found predominantly in the MSI cell lines; cells with mutant forms of TGF $\beta$ R 2 did not slow proliferation in response to TGF- $\beta$. The most frequent mutation was a single base-pair deletion in the $\mathrm{A}_{10}$ sequence; Markowitz et al demonstrated that this mutation made the protein nonfunctional. ${ }^{76}$ Furthermore, the authors identified mutations in the $\mathrm{A}_{10}$ tract of $90 \%$ of 111 colorectal tumor samples found to have MSI, proving that this was a relevant site of this form of genomic instability. ${ }^{77}$ In a new paradigm, repetitive DNA sequences were proposed to be particularly sensitive to the loss of DNA MMR activity, resulting in frame-shift mutations that led to premature stop codons and gene inactivation.

Several other genes affected by MSI were then identified that encoded regulators of cell proliferation (GRB1, TCF-4, WISP3, activin receptor-2, insulin-like growth factor-2 receptor, axin-2, and $C D X)$, the cell cycle or apoptosis (BAX, caspase-5, RIZ, BCL-10, PTEN, $h G 4-1$, and FAS), and DNA repair (MBD-4, BLM, CHK1, MLH3, RAD50, MSH3, and $M S H 6)^{78}$ (see Table 1). Remarkably, every human MMR gene except $M L H 1$ includes a mononucleotide repeat of at least $\mathrm{A}_{7}, 79$ so the process of MMR could become increasingly defective with cumulative losses of components on the system. ${ }^{80}$ However, it is not clear how many of the mutations at these loci are of functional significance (which has been determined for $T G F \beta R 2$ ), or whether some are simply markers of MSI, because biallelic inactivation of these genes has not been documented in all the tumors.

The identification of the proximate targets of carcinogenesis in the setting of defective MMR activity indicates that MSI-associated colorectal tumorigensis occurs through a different biological pathway compared to sporadic tumors. CRC cells with MSI can activate or inactivate the same signaling pathways as those without MSI, but different proteins within these pathways are involved. Genes are altered by different mechanisms in CRC cells with MSI compared to those without MSI. For example, sporadic colorectal tumors arise from a combination of mutations and $\mathrm{LOH}$, resulting in biallelic inactivation of $A P C$. Colorectal tumors with MSI have an increase in the number of point mutations compared to cancer cells without MSI, are more likely to be diploid, and do not have experienced 
widespread allelic imbalance or LOH. A substantial portion of colorectal tumors with MSI have normal expression of $A P C$, but have mutations in $\beta$ catenin that make it unable to interact with APC protein and undergo degradation, ${ }^{81,82}$ the biological equivalent of having no APC protein. Moreover, some colorectal tumors with MSI that have neither inactivated $A P C$ nor mutated $\beta$-catenin could have frame-shift mutations in factors further downstream in the WNT pathway, such as in the $\mathrm{A}_{9}$ sequence of $T C F-4$.

Of equal importance are the differences in the pathogenesis of colorectal tumors with MSI that come from patients with Lynch syndrome compared with sporadic CRC cells with CIMP, as illustrated in Figure 5. For reasons that are not clear, BRAF mutations are found in the majority of sporadic tumors with MSI but not in tumors that arise in patients with Lynch syndrome, which often have KRAS mutations. ${ }^{64,66}$ Activating mutations in $B R A F$ and $K R A S$ are functionally equivalent because their products function in series, in the mitogenactivated kinase signaling pathway, which regulates epithelial cell proliferation. ${ }^{83}$

\section{MSI and Inflammatory Bowel Disease}

The risk of CRC is increased in patients with inflammatory bowel disease, but it is not completely clear how chronic inflammation mediates carcinogenesis. Inflammation potentially increases mutagenesis via the generation of oxidative stress and formation of free radicals; mucosal repair involves the stimulation of proliferation, which could expand populations of colon cells with mutations that provide proliferative or survival advantages. However, studies in 2 different in vitro models have shown that oxidative stress can "relax" DNA MMR activity, ${ }^{84,85}$ and another study has demonstrated an increase in mutation rates in cells exposed to oxidative stress. ${ }^{86}$ So, at the time of greatest mutational load, the DNA MMR system is underactive - a biological paradox. The same has been reported for base excision repair, which might also lead to MSI. ${ }^{87}$

There is evidence for MSI in colon cells of patients with chronic ulcerative colitis. Using a panel of 5 dinucleotide repeat markers, Suzuki et al found that $21 \%$ of 63 colitis-associated tumors had at least 1 mutated microsatellite marker; a similar finding was reported for dysplastic lesions. ${ }^{88}$ Perhaps more surprisingly, Brentnall et al reported instability in at least 1 of 7 dinucleotide repeat markers in 50\% of non-neoplastic mucosa samples from individuals with chronic ulcerative colitis, but not in samples from patients with acute infectious colitis ${ }^{89}$; this finding was independently confirmed..$^{90}$ These studies were done before the MSI marker panels were standardized, but an unpublished review of the primary data indicated that only 1 dinucleotide repeat was mutated in each instance, indicating low level MSI (MSI-low) rather than high MSI level (MSI-high).

\section{Models of MSI}

Studies of MMR expanded from Escherichia coli and Saccharomyces cerevisiae to human cells and diseases in the mid-1990s. Parsons et al discovered that HCT116 cells had defects in MMR activity and $\mathrm{MSI}^{25}$ that were associated with biallelic mutations in MLH1. Stable transfer of human chromosome 3 into HCT116 (HCT116 + ch3 cells) restored MLH1 and created a model to study the role of MMR in the response to DNA damage and regulation of the cell cycle. ${ }^{91}$ MMR activity was restored in HCT116 + ch3 cells, which had reduced tolerance to DNA alkylation by $N$-methyl- $N$-nitro- $N$-nitrosoguani-dine. ${ }^{91}$ The model also demonstrated that MMR regulates passage through the $\mathrm{G}_{2} / \mathrm{M}$ cell cycle checkpoint and the response to 6-thioguanine, which is incorporated into DNA as guanine but acts like a mismatch in newly synthesized DNA. ${ }^{92}$ MMR activity is required to restrain clonal expansion of cells exposed to $N$-methyl- $N^{\prime}$-nitro- $N$-nitrosoguanidine and prevent proliferation of cells with damaged DNA. ${ }^{93}$ Cultured CRC cells with intact MMR activity were significantly more sensitive to therapeutic concentrations of 5-fluorouracil (5-FU; 5-10 
$\mu \mathrm{M})$ than DNA MMR- deficient cells, ${ }^{94}$ as well as other chemotherapeutics. ${ }^{95,96}$ This provided the theoretical basis for later observations that patients with MSI CRCs might not respond to traditional 5-FU- based chemotherapy.

Cell models were subsequently developed to study other genes in the DNA MMR family. Although stable transfer of human chromosome 3 corrected some DNA MMR activity, HCT116 + ch3 cells were still devoid of MSH3 activity. Therefore, the HCT116 + $3+5$ cell line was created by stable transfer of human chromosome 5 into HCT116 + ch3 cells, permitting an exploration of the effects of $M S H 3$ on MMR. ${ }^{97}$ The CRC cell line HCT15 does not express $M S H 6$ and the endometrial cancer cell line HEC59 does not express $M S H 2$ or MSH6. Stable transfer of human chromosome 2 (which contains MSH2 and MSHO) into these cells created cell lines that permitted analysis of the role of the MutS system in human cells. ${ }^{98}$ In the modified HCT15 and HEC59 cell lines, $M S H 2$ and MSH6 were re-expressed, MSI and the hyper-mutable phenotype were corrected (reducing mutations at the HPRT locus by $96 \%$ in HCT15), and the cells became more sensitive to cell death after exposure to mutagens. Similarly, in LoVo cells, which have defects at the MSH2 locus, MMR activity and sensitivity to mutagenic agents were restored following transfer of a fragment of chromosome $2 .{ }^{99}$

Lynch syndrome is an autosomal dominant disease, associated with the inheritance of a single mutated gene. However, in cultured cells, defects in MMR are recessive; a single copy of the gene restores DNA MMR activity. MMR activity is lost in cells that lack MSH2 or $M L H 1$, but only partially disrupted in cells without $M S H 6$ or $M S H 3$. These findings are important for understanding the pathogenesis of Lynch syndrome; patients with inactivating mutations in MSH6 develop an attenuated form of the disease and Lynch syndrome has not been associated with mutations in MSH3. ${ }^{100}$

\section{Stoichiometry of MMR Proteins}

HCT116 (deficient in $M L H 1$ ), LoVo (deficient in MSH2), HCT15 and DLD1 (deficient in MSH6), and SW48 (hypermethylated at MLHI) were used together with the single chromosome transfer-mediated restoration models and control lines (SW480, HEL, WI38) to study the stoichiometry of the members of the human DNA MMR system. ${ }^{101} \mathrm{MSH} 2$ was the most abundantly expressed MMR protein; cells expressed 3-5-fold more molecules than of its partner MLH1, depending upon the cell line studied. MSH6 protein was 4-12-fold more abundant than MSH3 protein and the combined amount of MSH6 and MSH3 expressed equaled that of MSH2 in cells. MSH6 might therefore have a more important role in DNA homeostasis than MSH3, and there are probably no other binding partners in the cell for MSH2. The relationship between expression levels of MSH2 and MLH1 have implications for MMR; a substantially larger number of MutS complexes are involved in identifying DNA mismatches than MutL complexes are required for interaction with the exonuclease complex. PMS2 was expressed in the lowest concentrations; the molar ratios of MLH1:PMS2 ranged from 1.4 to 2.75. Unfortunately, antibodies were not available to measure levels of PMS1 or MLH3 when these studies were performed. However, these studies helped provide a biochemical framework for the relative roles of $M S H 2$ and $M L H 1$ in MMR and their importance in human disease. Perhaps more importantly, these findings provided insight into the clinical differences between Lynch syndrome caused by mutations in $M S H 2$ and $M L H 1$, which have the most highly penetrant phenotypes, and the more attenuated phenotypes associated with germline mutations in MSH6 and PMS2. ${ }^{100}$

\section{Methylation of MLH1}

CIMP and the acquired form of MSI induced by hypermethylation of the MLH1 locus were studied in the CRC cell lines SW48 and RKO. SW48 cells do not express MLH1 or PMS2 
protein, ${ }^{101}$ they lack $M L H 1$ messenger RNA but do express stable PMS2 messenger RNA. Exposure of SW48 cells to the demethylating agent 5-aza-cytidine led to expression of the MLH1 messenger RNA and stable expression of the MLH1 and PMS2 proteins, which had been rapidly degraded in the absence of the stabilizing MLH1 protein. Demethylationinduced re-expression of $M L H 1$ and $P M S 2$ restored sensitivity to 5-FU, ${ }^{102}$ suggesting that demethylation might be used in conjunction with other therapeutic agents to overcome the drug resistance associated with acquired MSI in patients with CRC.

\section{Measuring MMR Deficiency}

Another model has been developed to measure mutation rates in cells with varying degrees of MMR deficiency. A green fluorescent protein reporter gene can used to identify sites of microsatellite mutation as a surrogate for a direct measurement of MMR activity (which is labor intensive) ${ }^{91}$ to quantify the effects of physiological manipulations. This technology has shown that oxidative stress induces relaxation of MMR activity and increases frameshift mutations. Furthermore, it has shown that mesalamine improves replication fidelity in cultured cells whereas aspirin does not. ${ }^{86,103}$

There is no naturally occurring animal model of MMR deficiency, but knockout strains of mice have been created for each of the Lynch syndrome genes: MSH2, ${ }^{104,105}$ MLH1, ${ }^{106,107}$ PMS2, ${ }^{107}$ and MSH6. ${ }^{108}$ In spite of contrary claims, none of the heterozygous knockout models produces a phenotype that is similar to the human disease. The principal tumors that develop in these mice are lymphomas. Homozygous disruption of MMR genes produces animals with a constitutional deficiency of MMR activity, a variety of interesting genetic lesions, and some intestinal tumors, but are not useful in screens for agents that have therapeutic or preventive effects in humans. Animals with compound knockouts of $A p c$ and a DNA MMR gene have accelerated polyp progression, but these tumors predominantly form in the small intestine. ${ }^{109}$

The study of MMR in mouse models is limited because human genes associated with colorectal carcinogenesis include coding microsatellites, in places where the mouse genes do not. Furthermore, genes that are associated with colorectal tumorigenesis encode factors that are required for cell proliferation and survival, such as TGF $\beta$ R2, BAX, and caspase-5, so it is a challenge to create mice with defects in these genes for cancer studies.

\section{MSI-High and MSI-Low}

At an international consensus meeting in 1997, the definition of MSI was standardized. ${ }^{110}$ The term MSI, when not otherwise modified, refers to MSH-high, in which $>30 \%$ of the microsatellite marker panel is mutated, as defined in the Bethesda guidelines. ${ }^{110}$ The definition of MSI-high permits the characterization of a group of CRCs with similar clinical and pathological characteristics. However, if enough different microsatellite markers are used, a larger proportion of CRCs will be found to have at least 1 mutated microsatellite. Those CRCs in which at least 1 but $<30 \%$ of the markers are mutated are called MSI-low and have clinical features of microsatellite-stable tumors. MSI-low has been observed in many tumor types. ${ }^{11-113}$

Another type of MSI has been recognized that does not fit into the definition of MSI-high. This signature has been called "elevated microsatellite alterations at selected tetranucleotide repeats" (EMAST). EMAST is most frequently found in noncolonic tumors and is associated with $p 53$ mutations. There is no evidence that it is caused by mutational inactivation of the MMR system. ${ }^{114}$

Haugen et al have resolved the mechanistic basis of MSI-L and EMAST. ${ }^{97}$ They found evidence for EMAST in $\sim 60 \%$ of sporadic CRCs and in all of the tumors that were MSI- 
high or MSI-low. EMAST was also found in 35 of 82 (42.6\%) of microsatellite-stable CRCs. Based on immunohistochemical analyses, $2 \%-50 \%$ of tumor cells were deficient in MSH3; its expression was heterogeneous throughout the tumor samples. Those parts of the tumor that did not express MSH3 were microdissected and found to be significantly more likely to have EMAST. Using in vitro models in which deficiencies in MMR can be studied in isolation, MSH3-deficient cells (including HCT116 + ch3, which has constitutional MSH3 deficiency, or cells in which MSH3 was conditionally knocked down), were found to have instability at di- and tetra-nucleotide repeats (ie, they had the EMAST and MSI-low phenotypes). This was important because MSI-low was detected through instability at dinucleotide repeat microsatellites. ${ }^{115}$ MSI-L and EMAST can therefore be induced by downregulation of $\mathrm{MSH} 3$, which occur heterogeneously (ie, non-clonally) throughout a tumor. It is possible that a similar mechanism is responsible for the appearance of MSI-low in the colonic mucosa of patients with chronic ulcerative colitis. ${ }^{89}$

\section{Diagnosis of MSI}

Patients with colorectal tumors with MSI have longer survival times than patients with tumors without MSI. ${ }^{10}$ A study of 175 patients with Lynch syndrome (120 of whom had Lynch syndrome-MLH1 type), compared to more than 14,000 population-based patients with CRC, showed that the 5-year cumulative relative survival for patients with Lynch syndrome was $65 \%$, compared to $44 \%$ of patients with sporadic CRC who were older than 65 years of age. ${ }^{116}$ A pooled analysis of MSI that included 32 studies and $7642 \mathrm{CRC}$ cases found an overall hazard ratio of 0.65 for patients with tumors that have MSI. ${ }^{51}$ Patients with Lynch syndrome have lower-stage disease when they are identified compared to patients with other types of CRC, and it is less common for patients with Lynch syndrome to present with metastatic disease. ${ }^{117-119}$ Gryfe et al reported that $17 \%$ of 607 CRC patients who were younger than 50 years old had MSI; the hazard ratio for patients with MSI-associated tumors was 0.42 , compared with patients in the same cohort with non-MSI tumors. Patients with tumors with MSI had lower mortality rates when patients were stratified by tumor stage, including patients with stage IV cancer. ${ }^{120}$

Tumors with MSI have greater numbers of tumor-infiltrating lymphocytes that are activated and cytotoxic; ${ }^{121}$ the lymphocytic reaction is independently associated with longer survival. ${ }^{122}$ Studies report that colorectal tumors with lymphocytic infiltrates are associated with longer survival times; in fact, lymphocyte infiltration may be a better prognostic factor than routine pathology staging. ${ }^{123}$ Abnormal results from immunohistochemical analyses of MSH2 and MLH1 independently predict better outcomes in patients with stage II-T3 colorectal tumors. ${ }^{124}$ Therefore, detection of MSI in a patient with CRC is a positive prognostic factor, particularly among young patients.

However, not all studies have confirmed the value of MSI detection in prognosis. ${ }^{125,126}$ This might be because there are technical challenges in identifying tumors with MSI. Some studies could have included CRC cases that were falsely reported to have MSI-positive tumors, which might have altered the modest differences in predicted patient outcomes. 126,127 Second, MSI analyses include 2 groups of patients: those with Lynch syndrome (who tend to be younger) and those with acquired methylation of the $M L H I$ gene (who are older). If Lynch syndrome patients are excluded from a cohort, the average age of patients with MSI is older- older patients have shorter overall survival times regardless of whether or not they have CRC. Most evidence, however, indicates that MSI predicts positive outcomes in patients with CRC.

The principal use of MSI testing in the clinic is to identify patients with Lynch syndrome. Approximately $15 \%$ of all colorectal tumors have MSI, and $75 \%-80 \%$ of this group have acquired methylation of $M L H 1$; only $\sim 2 \%-3 \%$ of all CRCs have germline mutations in one 
of the MMR genes. ${ }^{49}$ Although MSI analysis is the first approach to identifying patients with Lynch syndrome, immunohistochemical analysis is equivalent in levels of sensitivity and specificity and is accessible to most pathology laboratories. Identification of abnormally expressed proteins can be used to identify genes that should be sequenced. MSI identifies MMR-deficient colorectal tumors with approximately 93\% sensitivity; most insensitivity is caused by mutations in MSH6. ${ }^{128,129}$ Initial reports estimated that immunohistochemical analysis of MLH1 and MSH2 identified tumor samples with MMR defects with 92.3\% sensitivity and $100 \%$ specificity. ${ }^{122}$ A comprehensive review of 16 studies that compared MSI with immunohistochemical analysis of MLH1 and MSH2 proteins suggested that immunohistochemistry was somewhat less sensitive overall, mainly because of its poor performance with MLH1. However, when expression of MSH6 and PMS2 were included in the analyses, the performance of immunohistochemistry improved, resolving the problems encountered with samples from patients with Lynch syndrome caused by MSH6 and PMS2. ${ }^{129}$ The limitation of immunohistochemistry is that staining can be heterogeneous throughout the tumor, which affects the sensitivity of the test. ${ }^{129}$

Several panels of microsatellites have been used to diagnose MSI. The first consensus meeting recommended a panel of 3 dinucleotide repeats and 2 mono-nucleotide repeats that had been validated by a German consortium. ${ }^{110,111,130,131}$ This panel required that normal tissue be compared with tumor tissue, so many groups use a panel of 5 mononucleotide repeats that can be amplified and analyzed in a single assay. The location and nature of each of the microsatellite targets used for diagnostic purposes are listed in Table 2. The Pentaplex panel is as sensitive and specific as the initial panel proposed by the National Cancer Institute, but has some advantages that improve specificity. The $\mathrm{T}_{25}$ repeat in the $3^{\prime}$ untranslated region of caspase-2 is useful in detecting loss of MSH6.

\section{MSI as a Predictor of Response to Chemotherapy}

Tests for MSI can be used to predict patient response to adjuvant chemotherapy, although this practice is controversial. MMR genes were identified in bacteria; inactivating mutations created a mutator phenotype and allowed tolerance to DNA-damaging agents. ${ }^{132} \mathrm{~A}$ similar phenotype was found in mammalian cell lines. ${ }^{16,133}$ The stable correction of MMR activity in cell lines restored the cytotoxic response to alkylating agents, ${ }^{91,93}$ 6-thio-guanine, ${ }^{92} 5$ FU, ${ }^{94}$ platinum compounds, and other agents. ${ }^{96,134}$ This indicated that tumors with MSI might be resistant to some chemotherapeutic regimens.

However, the first study of the responsiveness of colorectal tumors with MSI reported just the opposite-tumors with MSI were more responsive to adjuvant chemotherapy than tumors without MSI. ${ }^{135}$ In this study, the assignment of patients to the treatment groups was flawed; instead of random assignment, oncologists selected patients for chemotherapy based on those with the fewest comorbidities and best performance status. Only 23 patients with MSI received chemotherapy, and the median age of these patients was 13 years younger than those who were not treated. Overall survival was significantly better in the MSI group, regardless of treatment. This created the impression that such patients were ideal candidates for adjuvant chemotherapy.

However, 11 subsequent studies have shown no benefit for chemotherapy among patients with colorectal tumors with MSI (see Table $3^{51,126,136-143}$ ). In the largest of these, a prospective, multicenter study in which patients were prospectively randomly assigned to treatment groups, the investigators found a nonsignificant, 2-fold excess in mortality among stage III CRC patients with MSI and a 3-fold increase in mortality among the stage II CRC patients with MSI. ${ }^{141}$ The MSI-associated increases in mortality might be related to the immunosuppressive effects of the treatment regimens, which would counter the increased anti-tumor immunity observed in patients with MSI. 
A study by Fallik et al associated inclusion of the topoisomerase-I inhibitor, irinotecan, in the chemotherapeutic regimen with increased survival times of in patients with MSIassociated CRC, ${ }^{144}$ a finding that has been supported by Bertagnolli et al. ${ }^{140}$ It is possible that a combination of drugs without excessive immunotoxicity is best for patients with MSIassociated CRC. There is no evidence for the efficacy of traditional 5-FU- based adjuvant chemotherapy in patients with MSI-associated CRC, but there might be regimens that would benefit these patients. Patients with MSI-associated CRC should be included in clinical trials until the appropriate treatment regimen is identified. Also, these studies did not distinguish whether the colorectal tumors with MSI were sporadic or inherited. Because most tumors with MSI are sporadic, it is likely that these observations are more relevant to those tumors; additional studies focused on patients with Lynch syndrome will be needed to confirm this concept.

\section{Acknowledgments}

Funding

Supported by grants from the National Cancer Institute and National Institutes of Health R01 CA72851 (to Dr Boland) and R01 CA129286 (to Drs Goel and Boland).

\section{Abbreviations used in this paper}

$\begin{array}{ll}\text { APC } & \text { adenomatous polyposis coli } \text { gene } \\ \text { CIMP } & \text { CpG island methylator phenotype } \\ \text { CRC } & \text { colorectal cancer } \\ \text { EMAST } & \text { elevated microsatellite alterations at selected tetranucleotide repeats } \\ \text { 5-FU } & \text { 5-fluorouracil } \\ \text { HNPCC } & \text { hereditary nonpolyposis colorectal cancer } \\ \text { IDL } & \text { insertion-deletion loop } \\ \text { LOH } & \text { loss of heterozygosity } \\ \text { MLH } & \text { Mut L homologue } \\ \text { MMR } & \text { mismatch repair } \\ \text { MSH } & \text { Mut S homologue } \\ \text { MSI } & \text { microsatellite instability } \\ \text { PCR } & \text { polymerase chain reaction } \\ \text { PMS1 } & \text { post-meiotic segregation- } 1 \\ \text { TGF- } \boldsymbol{B} & \text { transforming growth factor- } \beta \\ \text { TGF } \beta \text { R2 } & \text { TGF- } \beta \text { type II receptor }\end{array}$

\section{References}

1. Hanahan D, Weinberg RA. The hallmarks of cancer. Cell 2000;100:57-70. [PubMed: 10647931]

2. Wood LD, Parsons DW, Jones S, et al. The genomic landscapes of human breast and colorectal cancers. Science 2007;318:1108-1113. [PubMed: 17932254]

3. Fearon ER, Vogelstein B. A genetic model for colorectal tumorigenesis. Cell 1990;61:759-767. [PubMed: 2188735] 
4. Smith G, Carey FA, Beattie J, et al. Mutations in APC, Kirsten-ras, and p53-alternative genetic pathways to colorectal cancer. Proc Natl Acad Sci U S A 2002;99:9433-9438. [PubMed: 12093899]

5. Peinado MA, Malkhosyan S, Velazquez A, et al. Isolation and characterization of allelic losses and gains in colorectal tumors by arbitrarily primed polymerase chain reaction. Proc Natl Acad Sci U S A 1992;89:10065-10069. [PubMed: 1359533]

6. Kern SE, Fearon ER, Tersmette KW, et al. Clinical and pathological associations with allelic loss in colorectal carcinoma [corrected]. JAMA 1989;261:3099-3103. [PubMed: 2654431]

7. Vogelstein B, Fearon ER, Kern SE, et al. Allelotype of colorectal carcinomas. Science 1989;244:207-211. [PubMed: 2565047]

8. Ionov Y, Peinado MA, Malkhosyan S, et al. Ubiquitous somatic mutations in simple repeated sequences reveal a new mechanism for colonic carcinogenesis. Nature 1993;363:558-561. [PubMed: 8505985]

9. Blake C, Tsao JL, Wu A, et al. Stepwise deletions of polyA sequences in mismatch repair-deficient colorectal cancers. Am J Pathol 2001;158:1867-1870. [PubMed: 11337385]

10. Thibodeau SN, Bren G, Schaid D. Microsatellite instability in cancer of the proximal colon. Science 1993;260:816-819. [PubMed: 8484122]

11. Peltomaki P, Lothe RA, Aaltonen LA, et al. Microsatellite instability is associated with tumors that characterize the hereditary non-polyposis colorectal carcinoma syndrome. Cancer Res 1993;53:5853-5855. [PubMed: 8261393]

12. Aaltonen LA, Peltomaki P, Leach FS, et al. Clues to the pathogenesis of familial colorectal cancer. Science 1993;260:812-816. [PubMed: 8484121]

13. Grilley M, Holmes J, Yashar B, et al. Mechanisms of DNA-mismatch correction. Mutat Res 1990;236:253-267. [PubMed: 2144613]

14. Culligan KM, Meyer-Gauen G, Lyons-Weiler J, et al. Evolutionary origin, diversification and specialization of eukaryotic MutS homolog mismatch repair proteins. Nucleic Acids Res 2000;28:463-471. [PubMed: 10606644]

15. Acharya S, Wilson T, Gradia S, et al. hMSH2 forms specific mispair-binding complexes with hMSH3 and hMSH6. Proc Natl Acad Sci U S A 1996;93:13629-13634. [PubMed: 8942985]

16. Aquilina $G$, Hess $P$, Branch $P$, et al. A mismatch recognition defect in colon carcinoma confers DNA microsatellite instability and a mutator phenotype. Proc Natl Acad Sci U S A 1994;91:89058909. [PubMed: 8090742]

17. Palombo F, Gallinari P, Iaccarino I, et al. GTBP, a 160-kilodalton protein essential for mismatchbinding activity in human cells. Science 1995;268:1912-1914. [PubMed: 7604265]

18. Strand M, Earley MC, Crouse GF, et al. Mutations in the MSH3 gene preferentially lead to deletions within tracts of simple repetitive DNA in Saccharomyces cerevisiae. Proc Natl Acad Sci U S A 1995;92:10418-10421. [PubMed: 7479796]

19. Kunkel TA, Erie DA. DNA mismatch repair. Annu Rev Biochem 2005;74:681-710. [PubMed: 15952900]

20. Acharya S, Foster PL, Brooks P, et al. The coordinated functions of the E. coli MutS and MutL proteins in mismatch repair. Mol Cell 2003;12:233-246. [PubMed: 12887908]

21. Jascur T, Boland CR. Structure and function of the components of the human DNA mismatch repair system. Int J Cancer 2006;119:2030-2035. [PubMed: 16804905]

22. Boland CR, Fishel R. Lynch syndrome: form, function, proteins, and basketball. Gastroenterology 2005;129:751-755. [PubMed: 16083730]

23. Fishel R, Lescoe MK, Rao MR, et al. The human mutator gene homolog MSH2 and its association with hereditary nonpolyposis colon cancer. Cell 1993;75:1027-1038. [PubMed: 8252616]

24. Leach FS, Nicolaides NC, Papadopoulos N, et al. Mutations of a mutS homolog in hereditary nonpolyposis colorectal cancer. Cell 1993;75:1215-1225. [PubMed: 8261515]

25. Parsons R, Li GM, Longley MJ, et al. Hypermutability and mismatch repair deficiency in RER+ tumor cells. Cell 1993;75:1227-1236. [PubMed: 8261516]

26. Lynch HT, Smyrk TC, Watson P, et al. Genetics, natural history, tumor spectrum, and pathology of hereditary nonpolyposis colorectal cancer: an updated review. Gastroenterology 1993;104:15351549. [PubMed: 8482467] 
27. Lindblom A, Tannergard P, Werelius B, et al. Genetic mapping of a second locus predisposing to hereditary non-polyposis colon cancer. Nat Genet 1993;5:279-282. [PubMed: 7903889]

28. Bronner CE, Baker SM, Morrison PT, et al. Mutation in the DNA mismatch repair gene homologue hMLH1 is associated with hereditary non-polyposis colon cancer. Nature 1994;368:258-261. [PubMed: 8145827]

29. Papadopoulos N, Nicolaides NC, Wei YF, et al. Mutation of a mutL homolog in hereditary colon cancer. Science 1994;263:1625-1629. [PubMed: 8128251]

30. Nicolaides NC, Papadopoulos N, Liu B, et al. Mutations of two PMS homologues in hereditary nonpolyposis colon cancer. Nature 1994;371:75-80. [PubMed: 8072530]

31. Miyaki M, Konishi M, Tanaka K, et al. Germline mutation of MSH6 as the cause of hereditary nonpolyposis colorectal cancer. Nat Genet 1997;17:271-272. [PubMed: 9354786]

32. Kolodner RD, Tytell JD, Schmeits JL, et al. Germ-line msh6 mutations in colorectal cancer families. Cancer Res 1999;59:5068-5074. [PubMed: 10537275]

33. Vasen HF. Clinical description of the Lynch syndrome [hereditary nonpolyposis colorectal cancer (HNPCC)]. Fam Cancer 2005;4:219-225. [PubMed: 16136381]

34. Watson P, Vasen HF, Mecklin JP, et al. The risk of extra-colonic, extra-endometrial cancer in the Lynch syndrome. Int J Cancer 2008;123:444-449. [PubMed: 18398828]

35. Vasen HF, Mecklin JP, Khan PM, et al. The International Collaborative Group on Hereditary NonPolyposis Colorectal Cancer (ICG-HNPCC). Dis Colon Rectum 1991;34:424-425. [PubMed: 2022152]

36. Vasen HF, Watson P, Mecklin JP, et al. New clinical criteria for hereditary nonpolyposis colorectal cancer (HNPCC, Lynch syndrome) proposed by the International Collaborative group on HNPCC. Gastroenterology 1999;116:1453-1456. [PubMed: 10348829]

37. Boland CR. Evolution of the nomenclature for the hereditary colorectal cancer syndromes. Fam Cancer 2005;4:211-218. [PubMed: 16136380]

38. Peltomaki P. Lynch syndrome genes. Fam Cancer 2005;4:227-232. [PubMed: 16136382]

39. Lipkin SM, Wang V, Jacoby R, et al. MLH3: a DNA mismatch repair gene associated with mammalian microsatellite instability. Nat Genet 2000;24:27-35. [PubMed: 10615123]

40. Wu Y, Berends MJ, Post JG, et al. Germline mutations of EXO1 gene in patients with hereditary nonpolyposis colorectal cancer (HNPCC) and atypical HNPCC forms. Gastroenterology 2001;120:1580-1587. [PubMed: 11375940]

41. Alam NA, Gorman P, Jaeger EE, et al. Germline deletions of EXO1 do not cause colorectal tumors and lesions which are null for EXO1 do not have microsatellite instability. Cancer Genet Cytogenet 2003;147:121-127.

42. Lindor NM, Rabe K, Petersen GM, et al. Lower cancer incidence in Amsterdam-I criteria families without mismatch repair deficiency: familial colorectal cancer type X. JAMA 2005;293:1979_ 1985. [PubMed: 15855431]

43. Llor X, Pons E, Xicola RM, et al. Differential features of colorectal cancers fulfilling Amsterdam criteria without involvement of the mutator pathway. Clin Cancer Res 2005;11:7304-7310. [PubMed: 16243801]

44. Sellner LN, Taylor GR. MLPA and MAPH: new techniques for detection of gene deletions. Hum Mutat 2004;23:413-419. [PubMed: 15108271]

45. Wijnen J, van der Klift $\mathrm{H}$, Vasen $\mathrm{H}$, et al. MSH2 genomic deletions are a frequent cause of HNPCC. Nat Genet 1998;20:326-328. [PubMed: 9843200]

46. van der Klift H, Wijnen J, Wagner A, et al. Molecular characterization of the spectrum of genomic deletions in the mismatch repair genes MSH2, MLH1, MSH6, and PMS2 responsible for hereditary nonpolyposis colorectal cancer (HNPCC). Genes Chromosomes Cancer 2005;44:123138. [PubMed: 15942939]

47. Raevaara TE, Korhonen MK, Lohi H, et al. Functional significance and clinical phenotype of nontruncating mismatch repair variants of MLH1. Gastroenterology 2005;129:537-549. [PubMed: 16083711]

48. Lipkin SM, Rozek LS, Rennert G, et al. The MLH1 D132H variant is associated with susceptibility to sporadic colorectal cancer. Nat Genet 2004;36:694-699. [PubMed: 15184898] 
49. Hampel H, Frankel WL, Martin E, et al. Screening for the Lynch syndrome (hereditary nonpolyposis colorectal cancer). N Engl J Med 2005;352:1851-1860. [PubMed: 15872200]

50. Hampel H, Frankel WL, Martin E, et al. Feasibility of screening for Lynch syndrome among patients with colorectal cancer. J Clin Oncol 2008;26:5783-5788. [PubMed: 18809606]

51. Popat S, Hubner R, Houlston RS. Systematic review of micro-satellite instability and colorectal cancer prognosis. J Clin Oncol 2005;23:609-618. [PubMed: 15659508]

52. Ward R, Meagher A, Tomlinson I, et al. Microsatellite instability and the clinicopathological features of sporadic colorectal cancer. Gut 2001;48:821-829. [PubMed: 11358903]

53. Kane MF, Loda M, Gaida GM, et al. Methylation of the hMLH1 promoter correlates with lack of expression of hMLH1 in sporadic colon tumors and mismatch repair-defective human tumor cell lines. Cancer Res 1997;57:808-811. [PubMed: 9041175]

54. Veigl ML, Kasturi L, Olechnowicz J, et al. Biallelic inactivation of hMLH1 by epigenetic gene silencing, a novel mechanism causing human MSI cancers. Proc Natl Acad Sci U S A 1998;95:8698-8702. [PubMed: 9671741]

55. Wang L, Cunningham JM, Winters JL, et al. BRAF mutations in colon cancer are not likely attributable to defective DNA mismatch repair. Cancer Res 2003;63:5209-5212. [PubMed: 14500346]

56. Sinicrope FA, Rego RL, Halling KC, et al. Prognostic impact of microsatellite instability and DNA ploidy in human colon carcinoma patients. Gastroenterology 2006;131:729-737. [PubMed: 16952542]

57. Kakar S, Burgart LJ, Thibodeau SN, et al. Frequency of loss of hMLH1 expression in colorectal carcinoma increases with advancing age. Cancer 2003;97:1421-1427. [PubMed: 12627505]

58. Toyota M, Ahuja N, Ohe-Toyota M, et al. CpG island methylator phenotype in colorectal cancer. Proc Natl Acad Sci U S A 1999;96:8681-8686. [PubMed: 10411935]

59. Issa JP. CpG island methylator phenotype in cancer. Nat Rev Cancer 2004;4:988-993. [PubMed: 15573120]

60. Kondo Y, Issa JP. Epigenetic changes in colorectal cancer. Cancer Metastasis Rev 2004;23:29-39. [PubMed: 15000147]

61. Issa JP, Baylin SB, Belinsky SA. Methylation of the estrogen receptor $\mathrm{CpG}$ island in lung tumors is related to the specific type of carcinogen exposure. Cancer Res 1996;56:3655-3658. [PubMed: 8706002]

62. Issa JP, Ahuja N, Toyota M, et al. Accelerated age-related CpG island methylation in ulcerative colitis. Cancer Res 2001;61:3573-3577. [PubMed: 11325821]

63. Goel A, Nagasaka T, Arnold CN, et al. The CpG island methylator phenotype and chromosomal instability are inversely correlated in sporadic colorectal cancer. Gastroenterology 2007;132:127138. [PubMed: 17087942]

64. Ogino S, Nosho K, Kirkner GJ, et al. CpG island methylator phenotype, microsatellite instability, BRAF mutation and clinical outcome in colon cancer. Gut 2009;58:90-96. [PubMed: 18832519]

65. Deng G, Nguyen A, Tanaka H, et al. Regional hypermethylation and global hypomethylation are associated with altered chromatin conformation and histone acetylation in colorectal cancer. Int $\mathrm{J}$ Cancer 2006;118:2999-3005. [PubMed: 16425274]

66. Nagasaka T, Koi M, Kloor M, et al. Mutations in both KRAS and BRAF may contribute to the methylator phenotype in colon cancer. Gastroenterology 2008;134:1950-1960. [PubMed: 18435933]

67. Boland CR, Shin SK, Goel A. Promoter methylation in the genesis of gastrointestinal cancer. Yonsei Med J 2009;50:309-321. [PubMed: 19568590]

68. Gryfe R, Swallow C, Bapat B, et al. Molecular biology of colorectal cancer. Curr Probl Cancer 1997;21:233-300. [PubMed: 9438104]

69. Gazzoli I, Loda M, Garber J, et al. A hereditary nonpolyposis colorectal carcinoma case associated with hypermethylation of the MLH1 gene in normal tissue and loss of heterozygosity of the unmethylated allele in the resulting microsatellite instability-high tumor. Cancer Res 2002;62:3925-3928. [PubMed: 12124320]

70. Suter CM, Martin DI, Ward RL. Germline epimutation of MLH1 in individuals with multiple cancers. Nat Genet 2004;36:497-501. [PubMed: 15064764] 
71. Hitchins M, Williams R, Cheong K, et al. MLH1 germline epimutations as a factor in hereditary nonpolyposis colorectal cancer. Gastroenterology 2005;129:1392-1399. [PubMed: 16285940]

72. Chan TL, Yuen ST, Kong CK, et al. Heritable germline epimutation of MSH2 in a family with hereditary nonpolyposis colorectal cancer. Nat Genet 2006;38:1178-1183. [PubMed: 16951683]

73. Ligtenberg MJ, Kuiper RP, Chan TL, et al. Heritable somatic methylation and inactivation of MSH2 in families with Lynch syndrome due to deletion of the 3' exons of TACSTD1. Nat Genet 2009;41:112-117. [PubMed: 19098912]

74. Morak M, Laner A, Scholz M, et al. Report on de-novo mutation in the MSH2 gene as a rare event in hereditary nonpolyposis colorectal cancer. Eur J Gastroenterol Hepatol 2008;20:1101-1105. [PubMed: 19047842]

75. Markowitz S, Wang J, Myeroff L, et al. Inactivation of the type II TGF-beta receptor in colon cancer cells with microsatellite instability. Science 1995;268:1336-1338. [PubMed: 7761852]

76. Wang J, Sun L, Myeroff L, et al. Demonstration that mutation of the type II transforming growth factor beta receptor inactivates its tumor suppressor activity in replication error-positive colon carcinoma cells. J Biol Chem 1995;270:22044-22049. [PubMed: 7665626]

77. Parsons R, Myeroff LL, Liu B, et al. Microsatellite instability and mutations of the transforming growth factor beta type II receptor gene in colorectal cancer. Cancer Res 1995;55:5548-5550. [PubMed: 7585632]

78. Duval A, Hamelin R. Mutations at coding repeat sequences in mismatch repair-deficient human cancers: toward a new concept of target genes for instability. Cancer Res 2002;62:2447-2454. [PubMed: 11980631]

79. Chang DK, Metzgar D, Wills C, et al. Microsatellites in the eukaryotic DNA mismatch repair genes as modulators of evolutionary mutation rate. Genome Res 2001;11:1145-1146. [PubMed: 11435395]

80. Perucho M. Microsatellite instability: the mutator that mutates the other mutator. Nat Med 1996;2:630-631. [PubMed: 8640546]

81. Mirabelli-Primdahl L, Gryfe R, Kim H, et al. Beta-catenin mutations are specific for colorectal carcinomas with microsatellite instability but occur in endometrial carcinomas irrespective of mutator pathway. Cancer Res 1999;59:3346-3351. [PubMed: 10416591]

82. Miyaki M, Iijima T, Kimura J, et al. Frequent mutation of beta-catenin and APC genes in primary colorectal tumors from patients with hereditary nonpolyposis colorectal cancer. Cancer Res 1999;59:4506-4509. [PubMed: 10493496]

83. Rajagopalan H, Bardelli A, Lengauer C, et al. Tumorigenesis: RAF/RAS oncogenes and mismatchrepair status. Nature 2002;418:934. [PubMed: 12198537]

84. Chang CL, Marra G, Chauhan DP, et al. Oxidative stress inactivates the human DNA mismatch repair system. Am J Physiol Cell Physiol 2002;283:C148-C154. [PubMed: 12055083]

85. Lee SH, Chang DK, Goel A, et al. Microsatellite instability and suppressed DNA repair enzyme expression in rheumatoid arthritis. J Immunol 2003;170:2214-2220. [PubMed: 12574395]

86. Gasche C, Chang CL, Rhees J, et al. Oxidative stress increases frameshift mutations in human colorectal cancer cells. Cancer Res 2001;61:7444-7448. [PubMed: 11606378]

87. Hofseth LJ, Khan MA, Ambrose M, et al. The adaptive imbalance in base excision-repair enzymes generates microsatellite instability in chronic inflammation. J Clin Invest 2003;112:1887-1894. [PubMed: 14679184]

88. Suzuki H, Harpaz N, Tarmin L, et al. Microsatellite instability in ulcerative colitis-associated colorectal dysplasias and cancers. Cancer Res 1994;54:4841-4844. [PubMed: 8069848]

89. Brentnall TA, Crispin DA, Bronner MP, et al. Microsatellite instability in nonneoplastic mucosa from patients with chronic ulcerative colitis. Cancer Res 1996;56:1237-1240. [PubMed: 8640805]

90. Lyda MH, Noffsinger A, Belli J, et al. Microsatellite instability and K-ras mutations in patients with ulcerative colitis. Hum Pathol 2000;31:665-671. [PubMed: 10872658]

91. Koi M, Umar A, Chauhan DP, et al. Human chromosome 3 corrects mismatch repair deficiency and microsatellite instability and reduces $\mathrm{N}$-methyl-N'-nitro-N-nitrosoguanidine tolerance in colon tumor cells with homozygous hMLH1 mutation. Cancer Res 1994;54:4308-4312. [PubMed: 8044777] 
92. Hawn MT, Umar A, Carethers JM, et al. Evidence for a connection between the mismatch repair system and the G2 cell cycle checkpoint. Cancer Res 1995;55:3721-3725. [PubMed: 7641183]

93. Carethers JM, Hawn MT, Chauhan DP, et al. Competency in mismatch repair prohibits clonal expansion of cancer cells treated with N-methyl-N'-nitro-N-nitrosoguanidine. J Clin Invest 1996;98:199-206. [PubMed: 8690794]

94. Carethers JM, Chauhan DP, Fink D, et al. Mismatch repair proficiency and in vitro response to 5fluorouracil. Gastroenterology 1999;117:123-131. [PubMed: 10381918]

95. Aebi S, Kurdi-Haidar B, Gordon R, et al. Loss of DNA mismatch repair in acquired resistance to cisplatin. Cancer Res 1996;56:3087-3090. [PubMed: 8674066]

96. Fink D, Nebel S, Aebi S, et al. The role of DNA mismatch repair in platinum drug resistance. Cancer Res 1996;56:4881-4886. [PubMed: 8895738]

97. Haugen AC, Goel A, Yamada K, et al. Genetic instability caused by loss of MutS homologue 3 in human colorectal cancer. Cancer Res 2008;68:8465-8472. [PubMed: 18922920]

98. Umar A, Koi M, Risinger JI, et al. Correction of hypermutability, N-methyl-N'-nitro-Nnitrosoguanidine resistance, and defective DNA mismatch repair by introducing chromosome 2 into human tumor cells with mutations in MSH2 and MSH6. Cancer Res 1997;57:3949-3955. [PubMed: 9307278]

99. Watanabe Y, Haugen-Strano A, Umar A, et al. Complementation of an hMSH2 defect in human colorectal carcinoma cells by human chromosome 2 transfer. Mol Carcinog 2000;29:37-49. [PubMed: 11020245]

100. Boland CR, Koi M, Chang DK, et al. The biochemical basis of microsatellite instability and abnormal immunohistochemistry and clinical behavior in Lynch Syndrome: from bench to bedside. Fam Cancer 2008;7:41-752. [PubMed: 17636426]

101. Chang DK, Ricciardiello L, Goel A, et al. Steady-state regulation of the human DNA mismatch repair system. J Biol Chem 2000;275:29178. [PubMed: 10979986]

102. Arnold CN, Goel A, Boland CR. Role of hMLH1 promoter hyper-methylation in drug resistance to 5-fluorouracil in colorectal cancer cell lines. Int J Cancer 2003;106:66-73. [PubMed: 12794758]

103. Gasche C, Chang CL, Natarajan L, et al. Identification of frame-shift intermediate mutant cells. Proc Natl Acad Sci U S A 2003;100:1914-1919. [PubMed: 12578960]

104. Reitmair AH, Schmits R, Ewel A, et al. MSH2 deficient mice are viable and susceptible to lymphoid tumours. Nat Genet 1995;11:64-70. [PubMed: 7550317]

105. de WN, Dekker M, Berns A, et al. Inactivation of the mouse Msh2 gene results in mismatch repair deficiency, methylation tolerance, hyperrecombination, and predisposition to cancer. Cell 1995;82:321-330. [PubMed: 7628020]

106. Edelmann W, Cohen PE, Kane M, et al. Meiotic pachytene arrest in MLH1-deficient mice. Cell 1996;85:1125-1134. [PubMed: 8674118]

107. Yao X, Buermeyer AB, Narayanan L, et al. Different mutator phenotypes in Mlh1- versus Pms2deficient mice. Proc Natl Acad Sci U S A 1999;96:6850-6855. [PubMed: 10359802]

108. Edelmann W, Yang K, Umar A, et al. Mutation in the mismatch repair gene Msh6 causes cancer susceptibility. Cell 1997;91:467-477. [PubMed: 9390556]

109. Reitmair AH, Cai JC, Bjerknes M, et al. MSH2 deficiency contributes to accelerated APCmediated intestinal tumorigenesis. Cancer Res 1996;56:2922-2926. [PubMed: 8674041]

110. Boland CR, Thibodeau SN, Hamilton SR, et al. A National Cancer Institute Workshop on Microsatellite Instability for cancer detection and familial predisposition: development of international criteria for the determination of microsatellite instability in colorectal cancer Cancer Res 1998;58:5248-5257. [PubMed: 9823339]

111. Dietmaier W, Wallinger S, Bocker T, et al. Diagnostic microsatellite instability: definition and correlation with mismatch repair protein expression. Cancer Res 1997;57:4749-4756. [PubMed: 9354436]

112. Laiho $P$, Launonen V, Lahermo P, et al. Low-level microsatellite instability in most colorectal carcinomas. Cancer Res 2002;62:1166-1170. [PubMed: 11861399]

113. Halford SE, Sawyer EJ, Lambros MB, et al. MSI-low, a real phenomenon which varies in frequency among cancer types. J Pathol 2003;201:389-394. [PubMed: 14595750] 
114. Ahrendt SA, Decker PA, Doffek K, et al. Microsatellite instability at selected tetranucleotide repeats is associated with p53 mutations in non-small cell lung cancer. Cancer Res 2000;60:2488-2491. [PubMed: 10811129]

115. Jass JR, Young J, Leggett BA. Biological significance of micro-satellite instability-low (MSI-L) status in colorectal tumors. Am J Pathol 2001;158:779-781. [PubMed: 11159215]

116. Sankila R, Aaltonen LA, Jarvinen HJ, et al. Better survival rates in patients with MLH1associated hereditary colorectal cancer. Gastroenterology 1996;110:682-687. [PubMed: 8608876]

117. Watson P, Lin KM, Rodriguez-Bigas MA, et al. Colorectal carcinoma survival among hereditary nonpolyposis colorectal carcinoma family members. Cancer 1998;83:259-266. [PubMed: 9669808]

118. Aarnio M, Mustonen H, Mecklin JP, et al. Prognosis of colorectal cancer varies in different highrisk conditions. Ann Med 1998;30:75-80. [PubMed: 9556092]

119. Malesci A, Laghi L, Bianchi P, et al. Reduced likelihood of metastases in patients with microsatellite-unstable colorectal cancer. Clin Cancer Res 2007;13:3831-3839. [PubMed: 17606714]

120. Gryfe R, Kim H, Hsieh ET, et al. Tumor microsatellite instability and clinical outcome in young patients with colorectal cancer. N Engl J Med 2000;342:69-77. [PubMed: 10631274]

121. Phillips SM, Banerjea A, Feakins R, et al. Tumour-infiltrating lymphocytes in colorectal cancer with microsatellite instability are activated and cytotoxic. Br J Surg 2004;91:469-475. [PubMed: 15048750]

122. Ogino S, Nosho K, Irahara N, et al. Lymphocytic reaction to colorectal cancer is associated with longer survival, independent of lymph node count, microsatellite instability, and $\mathrm{CpG}$ island methylator phenotype. Clin Cancer Res 2009;15:6412-6420. [PubMed: 19825961]

123. Galon J, Costes A, Sanchez-Cabo F, et al. Type, density, and location of immune cells within human colorectal tumors predict clinical outcome. Science 2006;313:1960-1964. [PubMed: 17008531]

124. Parc Y, Gueroult S, Mourra N, et al. Prognostic significance of microsatellite instability determined by immunohistochemical staining of MSH2 and MLH1 in sporadic T3NOM0 colon cancer. Gut 2004;53:371-375. [PubMed: 14960518]

125. Barnetson RA, Tenesa A, Farrington SM, et al. Identification and survival of carriers of mutations in DNA mismatch-repair genes in colon cancer. N Engl J Med 2006;354:2751-2763. [PubMed: 16807412]

126. Kim GP, Colangelo LH, Wieand HS, et al. Prognostic and predictive roles of high-degree microsatellite instability in colon cancer: a National Cancer Institute-National Surgical Adjuvant Breast and Bowel Project Collaborative Study. J Clin Oncol 2007;25:767-772. [PubMed: 17228023]

127. Boland CR. Clinical uses of microsatellite instability testing in colorectal cancer: an ongoing challenge. J Clin Oncol 2007;25:754-756. [PubMed: 17228016]

128. Hendriks YM, Wagner A, Morreau H, et al. Cancer risk in hereditary nonpolyposis colorectal cancer due to MSH6 mutations: impact on counseling and surveillance. Gastroenterology 2004;127:17-25. [PubMed: 15236168]

129. Shia J. Immunohistochemistry versus microsatellite instability testing for screening colorectal cancer patients at risk for hereditary nonpolyposis colorectal cancer syndrome. Part I. The utility of immunohistochemistry. J Mol Diagn 2008;10:293-300. [PubMed: 18556767]

130. Suraweera N, Duval A, Reperant M, et al. Evaluation of tumor microsatellite instability using five quasimonomorphic mononucleotide repeats and pentaplex PCR. Gastroenterology 2002;123:1804-1811. [PubMed: 12454837]

131. Bocker T, Diermann J, Friedl W, et al. Microsatellite instability analysis: a multicenter study for reliability and quality control. Cancer Res 1997;57:4739-4743. [PubMed: 9354434]

132. Fishel R. The selection for mismatch repair defects in hereditary nonpolyposis colorectal cancer: revising the mutator hypothesis. Cancer Res 2001;61:7369-7374. [PubMed: 11606363]

133. Bhattacharyya NP, Skandalis A, Ganesh A, et al. Mutator phenotypes in human colorectal carcinoma cell lines. Proc Natl Acad Sci U S A 1994;91:6319-6323. [PubMed: 8022779] 
134. Aebi S, Fink D, Gordon R, et al. Resistance to cytotoxic drugs in DNA mismatch repair-deficient cells. Clin Cancer Res 1997;3:1763-1767. [PubMed: 9815561]

135. Elsaleh H, Joseph D, Grieu F, et al. Association of tumour site and sex with survival benefit from adjuvant chemotherapy in colorectal cancer. Lancet 2000;355:1745-1750. [PubMed: 10832824]

136. Storojeva I, Boulay JL, Heinimann K, et al. Prognostic and predictive relevance of microsatellite instability in colorectal cancer. Oncol Rep 2005;14:241-249. [PubMed: 15944796]

137. Lanza G, Gafa R, Santini A, et al. Immunohistochemical test for MLH1 and MSH2 expression predicts clinical outcome in stage II and III colorectal cancer patients. J Clin Oncol 2006;24:2359-2367. [PubMed: 16710035]

138. Jover R, Zapater P, Castells A, et al. Mismatch repair status in the prediction of benefit from adjuvant fluorouracil chemotherapy in colorectal cancer. Gut 2006;55:848-855. [PubMed: 16299036]

139. Des Guetz G, Schischmanoff O, Nicolas P, et al. Does micro-satellite instability predict the efficacy of adjuvant chemotherapy in colorectal cancer? A systematic review with meta-analysis. Eur J Cancer 2009;45:1890-1896. [PubMed: 19427194]

140. Bertagnolli MM, Niedzwiecki D, Compton CC, et al. Microsatellite instability predicts improved response to adjuvant therapy with irinotecan, fluorouracil, and leucovorin in stage III colon cancer: Cancer and Leukemia Group B Protocol 89803. J Clin Oncol 2009;27:1814-1821. [PubMed: 19273709]

141. Ribic CM, Sargent DJ, Moore MJ, et al. Tumor microsatellite-instability status as a predictor of benefit from fluorouracil-based adjuvant chemotherapy for colon cancer. N Engl J Med 2003;349:247-257. [PubMed: 12867608]

142. Benatti P, Gafa R, Barana D, et al. Microsatellite instability and colorectal cancer prognosis. Clin Cancer Res 2005;11:8332-8340. [PubMed: 16322293]

143. de Vos tot Nederveen Cappel WH, Meulenbeld HJ, Kleibeuker JH, et al. Survival after adjuvant 5-FU treatment for stage III colon cancer in hereditary nonpolyposis colorectal cancer. Int $\mathrm{J}$ Cancer 2004;109:468-471. [PubMed: 14961589]

144. Fallik D, Borrini F, Boige V, et al. Microsatellite instability is a predictive factor of the tumor response to irinotecan in patients with advanced colorectal cancer. Cancer Res 2003;63:57385744. [PubMed: 14522894] 


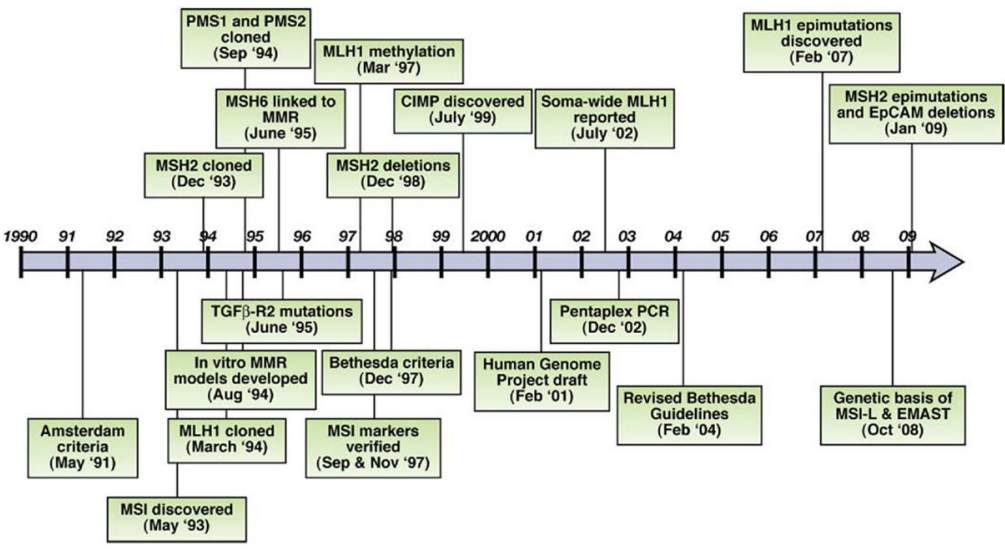

Figure 1.

MSI research associated with colorectal cancer from 1990 to 2010. EpCAM, epithelial cell adhesion molecule. 


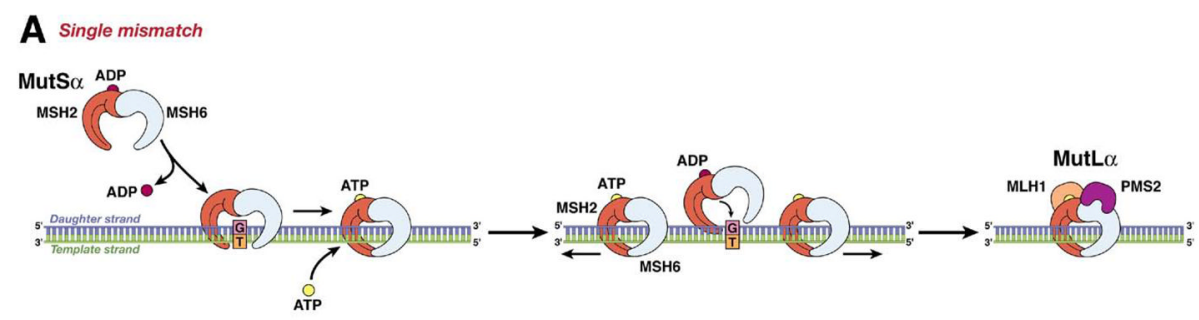

B Exonuclease complex and resynthesis

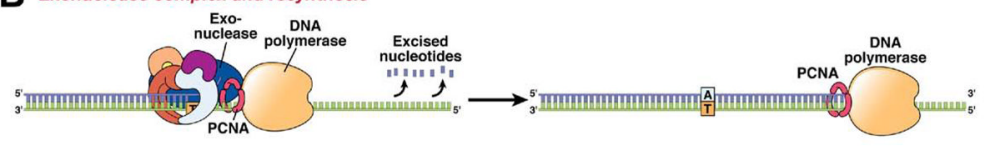

C Insertion/deletion loop and variations in MutL complexes

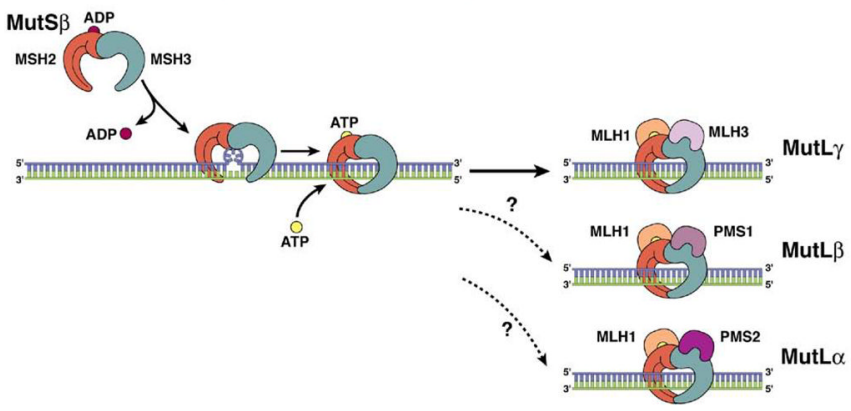

Figure 2.

The DNA MMR system functions through a series of steps. (A) MSH2-MSH6 (MutS $\alpha$ ) recognizes single base-pair mismatches, in which the DNA polymerase has matched the wrong base $(\mathrm{G})$ with the $\mathrm{T}$ on the template (shown on left), and creates a sliding clamp around the DNA. This step that requires the exchange of adenosine triphoshpate (ATP) for adenosine diphosphate (ADP) (by MSH2, but not MSH6 or MSH3). The complex diffuses away from the mismatch site, which is then bound by the MLH1-PMS2 (MutL $\alpha$ ) complex (right). This "matchmaker" complex moves along the new DNA chain until it encounters the DNA polymerase complex. $(B)$ The DNA MMR protein sliding clamp interacts with exonuclease-1, proliferating cell nuclear antigen (PCNA), and DNA polymerase. This complex excises the daughter strand back to the site of the mismatch (shown on left). Eventually, the complex falls off the DNA and resynthesis occurs, correcting the error. $(C)$ Variations on the DNA MMR theme. Whereas MSH2-MSH6 recognizes single pair mismatches and small IDLs, MSH2-MSH3 (MutS $\beta$ ) complements this by also recognizing larger IDLs (shown on left). The right side shows the possible interactions with different MutL dimers, as MLH1 can dimerize with PMS2, PMS1, or MLH3. The preferred interaction with MSH2-MSH3 is MLH1-MLH3 (MutL $\gamma$ ), but the precise roles of the other MutL heterodimers in this reaction are not entirely understood. 


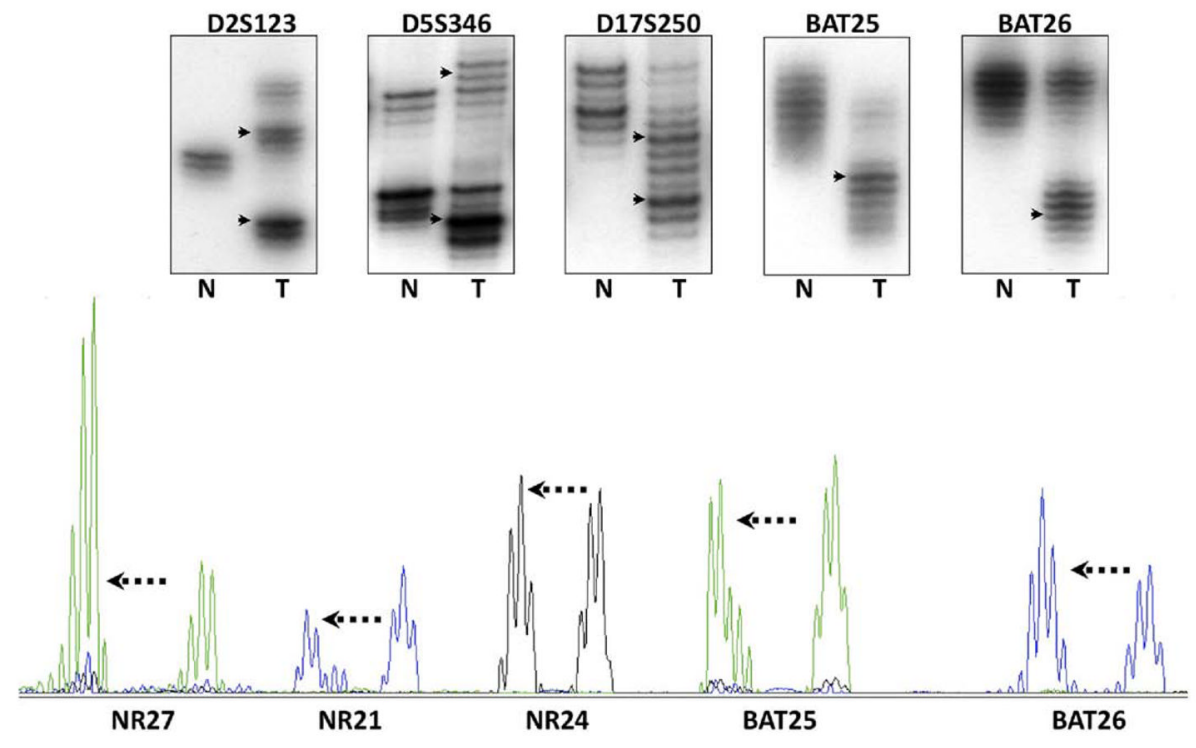

Figure 3.

MSI was initially discovered by autoradiography analyses of the PCR products after separation by gel electrophoresis (upper panel). $\mathrm{N}$ refers to DNA from the normal colon, and $\mathrm{T}$ from the tumor. The DNA polymerase used in PCR also has difficulty with the accurate amplification of templates, which is thought to be the explanation for the "ladder" of DNA bands that can be seen in the lanes for normal and tumor DNA. The upper panel illustrates the use of the 5 markers recommended by the National Cancer Institute consensus group; these consist of 3 dinucleotide repeats and 2 mononucleotide repeats (BAT25 and BAT26). In each instance, the DNA in the tumor has undergone somatic mutations (frequently, but not always, deletions), and the PCR product migrates to a different position on the gel, as indicated by the arrowheads. The lower panel shows the PCR products as they are analyzed by most laboratories using automated DNA sequencing with fluorescent primers. In this instance, 5 mononucleotide repeats have been analyzed, and in each instance, the mutations consist of deletions with different electrophoretic mobility (mutant alleles indicated by the arrows). 


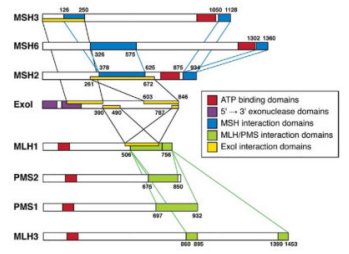

Figure 4.

The regions of protein-protein interactions among the members of the MMR system. Mutations in the regions of protein interactions are particularly likely to disrupt MMR function. Key interactions are illustrated among the MutS proteins, among the MutL proteins, and between these proteins and Exo1. ATP, adenosine triphosphate; PMS, postmeiotic segregation. 


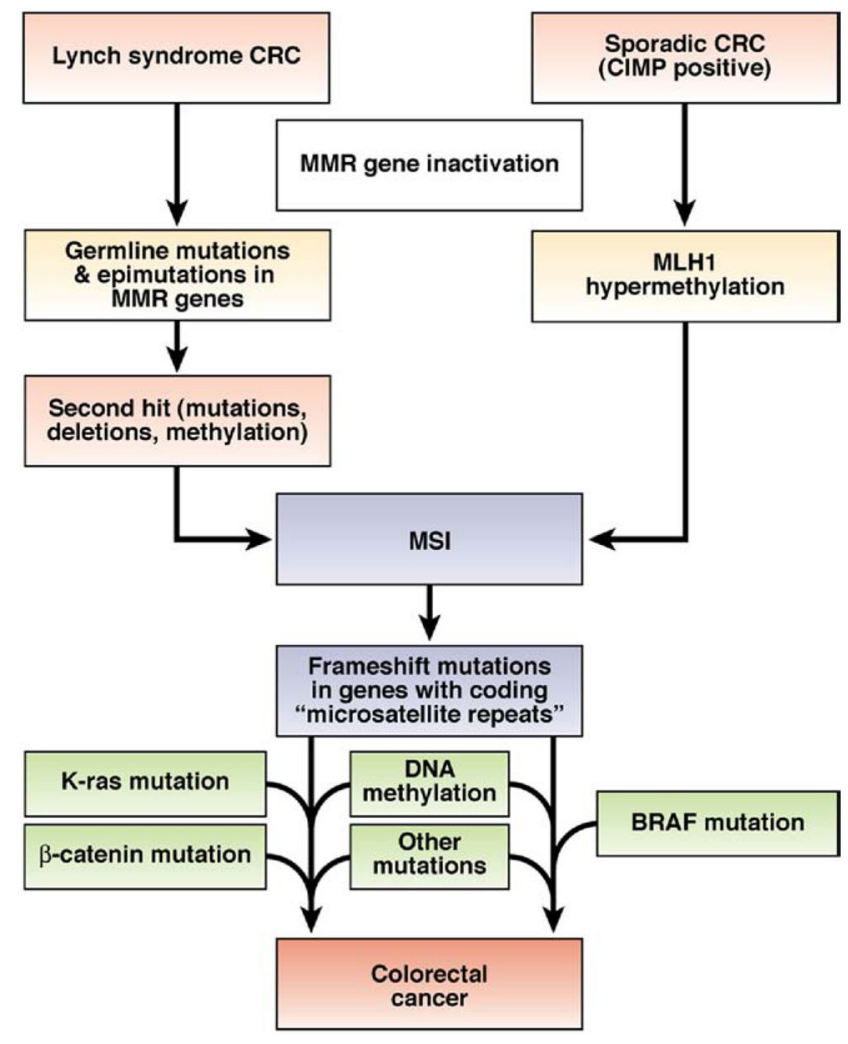

Figure 5.

There are 2 molecular pathways to the development of CRC with MSI. Approximately $20 \%-25 \%$ of colorectal tumors with MSI arise in individuals with Lynch syndrome. These tumors contain a germline mutation in one of the MMR genes, followed by a second hit to the wild-type copy (inherited from the unaffected parent); this could occur via LOH, methylation, or point mutation. Defects in MMR result in MSI and rapid accumulation of somatic mutations. It has been proposed that tumors arise via mutations in a few critical genes, but that large numbers of microsatellite mutations also occur-most of which are simply passengers that provide the mutational signature used to identify tumors with MSI. Colorectal tumors that arise in patients with Lynch syndrome often have mutations in KRAS. Most cases of CRC associated with MSI are not inherited (familial), but arise through sporadic methylation-induced silencing of $M L H 1$. These sporadic tumors have the CIMP signature, resulting in methylation of many gene promoters. When the $M L H 1$ promoter is methylated, MMR activity fails and MSI ensues. Thus, the mutational signature of sporadic tumors includes CIMP and MSI. BRAF mutations are also observed in most sporadic colorectal tumors, but do not occur in tumors of patients with Lynch syndrome. 
Table 1

The Genetic Targets of Microsatellite Instability in Colorectal Cancer

\begin{tabular}{|c|c|}
\hline Microsatellite length & Gene \\
\hline \multirow[t]{6}{*}{ A 10} & AIM2 \\
\hline & CASPASE-5 \\
\hline & $M B D-4$ \\
\hline & $O G T$ \\
\hline & SEC63 (also, A9) \\
\hline & $T G F \beta_{1} R 2$ \\
\hline \multirow[t]{9}{*}{ A9 } & $B L M$ \\
\hline & CHK1 \\
\hline & $G R B-14$ \\
\hline & $M L H 3$ \\
\hline & $R A D 50$ \\
\hline & RHAMM \\
\hline & RIZ (also, A8) \\
\hline & $T C F-4$ \\
\hline & WISP3 \\
\hline \multirow[t]{5}{*}{ A8 } & $A C V R I I$ \\
\hline & $A P A F$ \\
\hline & $B C L-10$ \\
\hline & $h G 4-1$ \\
\hline & MSH3 \\
\hline A6 & PTEN (2 A6's) \\
\hline $\mathrm{T} 10$ & $O G T$ \\
\hline \multirow[t]{2}{*}{ T9 } & KIAA0971 \\
\hline & $N A D H-U O B$ \\
\hline \multirow[t]{2}{*}{ G8 } & $B A X$ \\
\hline & $I G F 2 R$ \\
\hline C9 & $S L C 23 A 1$ \\
\hline $\mathrm{C} 8$ & MSH6 \\
\hline \multirow[t]{2}{*}{ G7 } & $A X I N-2(A 6, A 6, C 6)$ \\
\hline & $C D X 2$ \\
\hline $\mathrm{T} 7$ & $F A S$ \\
\hline
\end{tabular}

Data from Duval and Hamelin. ${ }^{78}$ 
Table 2

Microsatellite Markers Used in Diagnosis of Microsatellite Instability in Colorectal Cancer

\begin{tabular}{|c|c|c|c|c|}
\hline Marker & Gene & MS repeat & Chromosomal location & Location of MS repeat \\
\hline $\mathrm{D} 2 \mathrm{~S} 123$ & Linked to MSH2 & $\mathrm{CA}(\mathrm{n})$ & $2 \mathrm{p} 16$ & \\
\hline D5S346 & Linked to APC & $\mathrm{CA}(\mathrm{n})$ & $5 q 22-23$ & \\
\hline D17S250 & Linked to p53 & $\mathrm{CA}(\mathrm{n})$ & $17 q 12$ & \\
\hline BAT-25 & c-kit & A (25) & $4 q 12$ & Intron 16 \\
\hline BAT-26 & $\mathrm{MSH} 2$ & A (26) & $2 \mathrm{p} 21$ & Intron 5 \\
\hline \multicolumn{5}{|c|}{ Pentaplex panel of mononucleotide repeat markers } \\
\hline BAT-25 & c-kit & A (25) & $4 q 12$ & Intron 16 \\
\hline BAT-26 & $\mathrm{MSH} 2$ & A (26) & $2 \mathrm{p} 21$ & Intron 5 \\
\hline NR-21 & SLC7A8 & $\mathrm{T}(21)$ & $14 q 11$ & 5' UTR \\
\hline NR-24 & Zinc finger $2(\mathrm{ZNF}-2)$ & $\mathrm{T}(24)$ & $2 q 11$ & 3' UTR \\
\hline NR-27 & Inhibitor of apoptosis protein-1 & A (27) & $11 \mathrm{q} 22$ & 5' UTR \\
\hline \multicolumn{5}{|c|}{ Other relevant microsatellite markers } \\
\hline CAT25 & Caspase-2 (CASP2) & $\mathrm{T}(25)$ & $7 q 34$ & 3' UTR \\
\hline
\end{tabular}

MS, microsatellite; NCI, National Cancer Institute. 


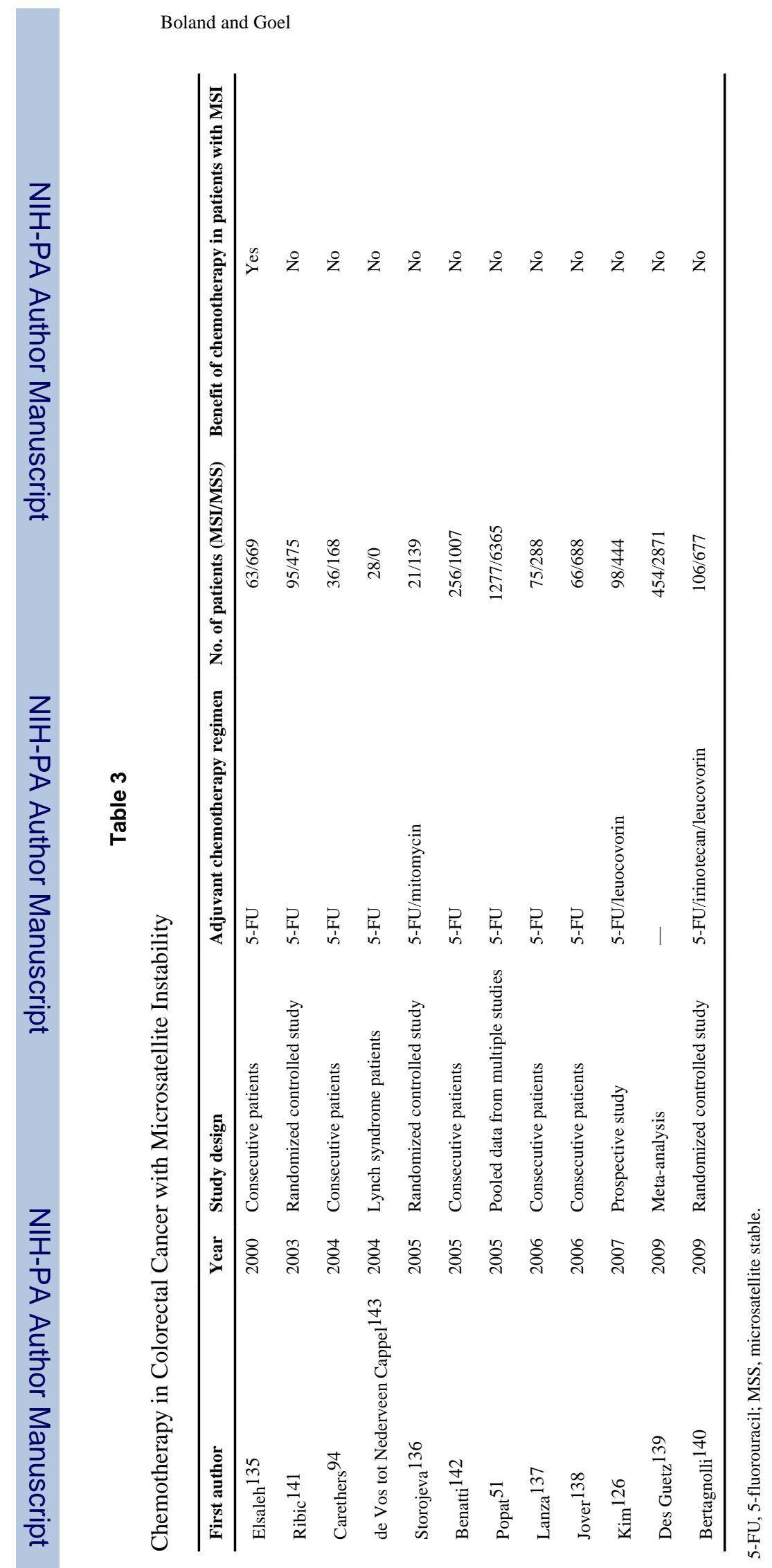

Gastroenterology. Author manuscript; available in PMC 2011 February 11. 